\title{
Up in the Air: Air Pollution and Crime - Evidence from India*
}

\author{
Tejendra Pratap Singh ${ }^{\dagger} \quad$ Sujata Visaria ${ }^{\ddagger}$ \\ This draft: May, 2021 \\ First draft: February, 2021
}

\begin{abstract}
Recent work from developed parts of the world has documented a positive association between air pollution and criminal activity. We use high-frequency complaints and air pollution data to estimate air pollution's causal effects on crime in a developing country. In order to establish causality, we exploit plausibly exogenous local variation in wind direction in an instrumental variable setup. We find that a lower number of complaints are received on the days of high air pollution levels. This effect is more pronounced for property crimes than for violent crimes. Our results are robust to a host of robustness checks and falsification checks. Exploring the potential mechanisms, we find that the decline in criminal activity might result from increased costs of indulging in criminal activity.
\end{abstract}

JEL Classifications: K42, O13, Q50, Q52, Q53

Keywords: Air Pollution, Crime, Environment, India

\footnotetext{
${ }^{*}$ Any remaining errors are our own.

${ }^{\dagger}$ Georgia State University. tpratapsingh1@student.gsu.edu

łHong Kong University of Science and Technology. svisaria@ust.hk
} 


\section{Introduction}

The health effects of air pollution exposure, both short-term and long-term, are widely studied both in the developed and developing country contexts. ${ }^{1,2}$ Increasingly researchers are looking at the effects of exposure to air pollution on various other development outcomes also. ${ }^{3}$ One such outcome that is receiving greater attention is the effect of exposure to air pollution on criminal activity (Bondy et al. (2020), Burkhardt et al. (2019), and Herrnstadt et al. (2020)). Despite the likelihood of the relationship being non-homogeneous between developing and developed regions, all the extant literature has focused on the developed part of the world. In this paper, we attempt to fill this gap.

We look at how an increase in ambient air pollution affects criminal activity in India. We use high-frequency data on the complaints received by the universe of the police stations in the state of Bihar. We merge this data on the criminal activity with the highresolution satellite reanalysis data on the fine particulate matter (PM2.5) concentration around the police station. In order to establish the causality of our estimates, we employ an instrumental variable strategy where we instrument for PM2.5 concentration by exploiting local variations in wind directions (Deryugina et al. (2019)).

Our results show that an increase in the average daily $P M 2.5$ concentration by $1 \mu \mathrm{g} / \mathrm{m}^{3}$ leads to a decrease in the daily number of First Information Report (FIR) received by 0.00032. In other words, the excess PM2.5 concentration above the safe limits suggested by the World Health Organization (WHO) leads to a reduction in daily criminal activity of approximately $10.9 \%$ of the sample average. Our data allows us to look at how the elevated air pollution levels impact violent crimes and property crimes separately. We find that the reduction in criminal activity due to high pollution levels is greater for property crimes than for violent crimes.

We establish the robustness of our results through a battery of robustness checks. Our main results are not altered by alternate estimators, alternate specifications, area around

\footnotetext{
${ }^{1}$ For studies on developed countries, see Anderson (2019), Austin et al. (2019), Beatty \& Shimshack (2011), Chay \& Greenstone (2003), Currie \& Neidell (2005), Currie et al. (2009), Currie \& Walker (2011), Currie et al. (2011), Deryugina et al. (2019), Jans et al. (2018), Moretti \& Neidell (2011), Neidell (2004), Schlenker \& Walker (2015), and Ward (2015).

${ }^{2}$ For studies on developing countries, see Arceo et al. (2016), Deschenes et al. (2020), Ghosh \& Mukherji (2014), Jayachandran (2009), Pullabhotla (2018), Rosales-Rueda \& Triyana (2018), Singh et al. (2019), and Rangel \& Vogl (2019).

${ }^{3}$ These are human capital (Bharadwaj et al. (2017), Ebenstein et al. (2016), Heissel et al. (2020), Marcotte (2017), Sanders (2012), and Singh (2020)), labor market outcomes (Aragón et al. (2017), Chang et al. (2016), Hanna \& Oliva (2015), and Isen et al. (2017)), cognitive functioning (Chen et al. (2018)), among other things.
} 
the police station over which we construct our measure of air pollution, dropping one year at a time from the estimation sample, and using the date of the incident instead of the date of FIR registration. We also establish the robustness of our results to alternative data sources. Specifically, we use the latest round of the two widely used survey dataDemographic and Health Survey (DHS) 2015-16 and India Human Development Survey (IHDS) 2011-12. Using the information in these surveys on criminal activities, we show that exposure to elevated ambient air pollution levels has a dampening effect on criminal activity. We also complement our police station level analysis by using novel data on the complaints received by the National Commission for Women (NCW). Although our results are not statistically significant at the conventional significance levels, our point estimates are in the same direction as that of our main results. This lends further credence to our main findings.

Exploring the potential mechanisms that might lead to observed findings, we find that increased costs of indulging in criminal activity could be a channel through which elevated air pollution levels can negatively impact criminal activity. We first show that the crimes that are unlikely to be affected by the higher pollution levels do not respond to elevated ambient air pollution. Using detailed data on the crimes, we are able to show that the negative effect of air pollution on criminal activity is more pronounced for property crimes than for violent crimes. Using novel data on the number of arrests made at each police station in our sample, we are able to rule out the channel of reduced effort exerted by the police on the days of relatively higher ambient air pollution.

Extant literature on the relationship between air pollution and criminal activity has focused exclusively on the developed countries. Herrnstadt et al. (2020) find that there is a decline in violent crimes on days of high air pollution but not the property crimes in Chicago. Burkhardt et al. (2019) uses data on county-level crimes in the US and finds that an increase in PM2.5 and Ozone is positively associated with violent crimes only. Bondy et al. (2020) study the effect of air pollution in London Boroughs. In contrast to the other two papers, Bondy et al. (2020) find that higher air pollution positively impacts crimes, and the effect is more pronounced for relatively more polluted days.

In section (3), we present a conceptual framework and argue why the results from previous work that focuses on criminal activity in the developed countries might not extrapolate to the developing countries, which is the setting of our study. For instance, it is possible that elevated pollution levels might increase the cost of committing a crime as there might be smaller potential targets on high pollution days. This increase in cost 
might be large enough to deter criminals from undertaking criminal activity and thus reduce the overall crime rate when the air quality is bad.

We contribute to multiple strands of literature. To the best of our knowledge this is the first paper that looks at the relationship between criminal activity and short run air pollution in a developing country. We contribute to the literature on developed countries studying the association between crime and air pollution by looking at it in a developing country setting (Bondy et al. (2020), Burkhardt et al. (2019), and Herrnstadt et al. (2020)). We also contribute to a large literature on the effects of environmental conditions on conflicts, both inter personal and at more aggregate levels (Burke et al. (2009), Doleac \& Sanders (2015), Fetzer (2020), Heilmann et al. (2021), Hsiang et al. (2011), Hsiang et al. (2013), Iyer \& Topalova (2014), Jacob et al. (2007), Ranson (2014)).

The rest of this paper is organized as follows. Section (2) gives background and context. Section (3) develops the conceptual framework. Section (4) discusses our data sources and presents descriptive statistics. Section (5) details our empirical strategy. We present results in section (6). In this section we also present robustness checks along with studying various channels that might lead to observed results. Section (7) concludes.

\section{Background and Context}

\subsection{Crime in Bihar}

As per the latest available national crime records number from 2019 published by the National Crime Records Bureau (NCRB), Bihar's per capita crime rate is lower than the national average. But this statistic does not reflect the complete picture of the state's crime situation. There has been an increase in the absolute number of crimes registered under the Indian Penal Code (IPC). Also, the period considered to be a phase of relatively less crime in Bihar after the change of regime in 2005 has seen an increase in the number of cases of attempted murders and kidnapping. The liquor prohibition initiated in 2016 in the state has created new avenues for criminal activity through the illicit liquor trade.

The state police are also grossly understaffed as there are many vacancies. These have only gone up in the last decade, with the latest available data from 2019 showing almost $40 \%$ of the vacant positions. Moreover, Bihar fares worse than the national per-capita police force availability. This has serious implications for law and order maintenance. Interestingly, Jharkhand, the neighboring state of Bihar, which was carved out of it, has 
better per-capita police force availability.

Over the years, Bihar police have tried to make it easy for citizens to register complaints. Anyone can register a complaint online. A framework in place mandates that appropriate action by the concerned authorities needs to be taken on the registered complaint within a given time frame. The availability of a complaint registration facility through a web-based application and voice call has allowed it to reach a large fraction of the population. This allows citizens to report the crime in real-time and allows authorities to maintain law and order in the state.

FIR is a document that records information on the commission of an alleged offense. It can be filed by the aggrieved person or any other person. It can be filed in written or orally. FIR is the first step towards any criminal proceeding that leads to the trial and subsequent punishment of a criminal.

\subsection{Air Pollution in Bihar}

Bihar, situated in the northern part of the country and being a part of the Indo-Gangetic plains, has one of India's worst air qualities. State capital city of Patna often ranks in the upper echelons of the ranking of the world's most polluted cities (Chowdhury \& Dey (2016), Ghude et al. (2016), Jia et al. (2020), Pal et al. (2018), Sahu et al. (2020), and Upadhyay et al. (2018)). ${ }^{4}$ Numerous studies have produced estimates of the huge health and mortality benefits of reducing ambient air pollution in north India. Bihar ranks at the top of the states where these plausible benefits are one of the largest (Jia et al. (2020), and Upadhyay et al. (2018)).

Air pollution in much of the Indo-Gangetic plains is seasonal. Air quality deteriorates in the post-summer harvest season that usually begins in September. Previous work has attributed this worsening in the air quality in this part of the country to various sources like stubble burning by the farmers to clear the fields for the upcoming winter sowing season, meteorological conditions that aid the trapping of the harmful pollutants in the lower layers of the atmosphere, etc. Air quality begins to improve in March when favorable weather conditions aid in faster dispersion of air pollutants. This improvement continues in the monsoon season. Figure 8 where we use the air pollution data to show the average monthly PM2.5 concentration in our sample reflects these observations.

\footnotetext{
${ }^{4}$ As per the ranking of the world's most polluted cities produced by the private organization IQAir, Patna ranked $22^{\text {nd }}$ for the year 2019.
} 


\section{Conceptual Framework}

Using the rational model of criminal behavior outlined in Becker (1968), we discuss how increased air pollution can affect criminal activity. In the model, the decision to commit a crime by the individual depends on the expected benefits and expected costs of committing the crime. Let $p$ be the probability of getting caught after committing the crime, $y$ be the benefit from committing the crime, $c$ be the cost of punishment if caught after committing the crime, $s$ be the cost incurred in committing the crime, and $f$ be the extent of police deployment to deter crimes. Let $u_{n}$ be the utility from not indulging in the criminal activity, $\mathfrak{u}_{c c} \equiv \mathfrak{u}(y, s, c)$ be the utility when caught after committing the crime, $\mathfrak{u}_{\mathfrak{c n}} \equiv \mathfrak{u}(\mathrm{y}, \mathrm{s})$ be the utility when not caught after committing the crime. We assume that $\frac{\partial u}{\partial y}>0, \frac{\partial u}{\partial s}<0, \frac{\partial u}{\partial c}<0$, and $\frac{\partial p}{\partial f}>0$. An individual will commit a crime if the expected utility from committing the crime is greater than the utility from not indulging in the criminal activity, i.e.,

$$
(1-p(f)) u_{n c}+p(f) u_{c c}>u_{n}
$$

Apriori, the effect of air pollution on criminal activity is ambiguous. Elevated air pollution levels can lead to increased incidence of respiratory problems, which can reduce the overall crime by virtue of increasing the cost of indulging in crime. This increase in cost might come from increased incapacitation of people, which reduces possible targets for the criminals. Higher occupation rates of properties as people stay home to reduce the exposure, which might reduce the property crimes like burglary and theft. Simultaneously, there might be a decrease in costs to indulge in criminal activity. This might result from the lower police force to deter crime after exposure to air pollution as the increased health issues might make members of the police force sick, lower people in public spaces can lead to an increase in criminal activity as there are lower potential witnesses resulting in a lower probability of getting caught and punished. Additionally, there might also be a decline in criminal activity as criminals themselves get sick, and therefore overall crime rate decreases after exposure to air pollution.

To the extent that exposure to air pollution changes criminal activity determinants, looking at different crimes can help us shed some light on the mechanism underlying various crimes. Suppose exposure to elevated air pollution levels results in changes to costs involved in indulging in criminal activity (s) and the extent of police deployment to deter crime (f). In that case, we should expect the property crimes to react to the changes 
in air pollution levels. Earlier work, while not casually identifying it, has talked about how elevated levels of air pollution result in more aggressive behavior, potentially leading to an increase in overall crime rate as it might increase the benefit (y) from indulging in criminal activity (Herrnstadt et al. (2020)). To the extent this association holds true in our sample, we should expect to see an increase in aggressive crimes like murder during high air pollution episodes.

\section{Data}

\subsection{Crime Data}

We use data on criminal activity from two sources. First, we use the First Information Reports (FIR) data from the state of Bihar. Second, we use the data on the number of complaints received by the National Commission for Women (NCW). NCW data is available at two temporal levels-daily and monthly. We describe each of these in detail below.

\subsubsection{FIR Data}

We use detailed data on the First Information Reports (FIR) registered at each police station in Bihar between 2015 and 2019. This data is publicly available and is compiled by State Crime Records Bureau (SCRB). This data contains detailed information on the criminal cases reported to each police station in the state. Each criminal record in the data has information on the date of registration of the FIR, date of the incident, various criminal procedures, and laws based on which the FIR is registered. This is the most granular level of information available on the criminal cases in the country (Imbert et al. (2016), and Poblete-Cazenave (2020)).

We create a daily panel of the number of FIRs registered at each police station using the information on the date of the registration of the FIR. We use information from all the 964 police stations in the state for which SCRB publishes data online. Figure 1 shows the locations of each police station in our sample. We see that the police stations are spatially distributed with small clusters in bigger cities like the capital city of Patna.

To establish the robustness of our results to the aggregation of the number of registered FIRs at the district level, we utilize the information available from SCRB on the district in which the police station is located. Police districts in Bihar are the second tier of police administrative division after the police range. Each police district in Bihar, with 
the exception of Patna, which a Senior Superintendent of Police heads, is headed by the Superintendent of Police. Using this information on which police district a police station falls under, we create a daily panel of the number of FIRs registered at the district level. Using the information on the date of the FIR registration for each police station in the district, we create a count of the number of registered FIRs for each day in our sample. We use the information on all the 47 police districts in the data reported by SCRB.

We classify the crimes into two broad categories of violent and property crimes using the information on the classification of crimes under various categories by the National Crime Records Bureau (NCRB). ${ }^{5}$ The two broad categories of crimes that we consider are property crimes and violent crimes. ${ }^{6}$

We present the descriptive statistics on the number of FIRs registered during our sample period in Table 1. We see that, on average, three new FIRs are registered during our sample period, with FIRs related to property crimes registered to be slightly higher than the FIRs related to the violent crimes. Figure 6 shows the distribution of FIRs in our sample over various temporal aggregates. We see that the number of FIRs registered annually increases each year during our sample period. Further, the distributions by month, calendar week, and day of the week show that there is temporal variation in the number of FIRs registered in our sample. Our empirical strategy exploits this temporal variation to study how exposure to elevated ambient air pollution levels affects criminal activity.

\subsubsection{Monthly NCW Complaints Data}

To complement our analysis based on the data from SCRB on registered FIRs, we use publicly available daily data on the number of complaints received by the National Commission for Women (NCW). NCW is a national organization and a statutory body of the Government of India that aims to protect and promote the interests of women. Women can report their grievances to NCW in several ways. They can either email, call, social media, or register their complaints via mail or in-person (Poblete-Cazenave (2020), and Ravindran \& Shah (2020)).

The NCW data is available for all the districts in the country for each month. Using

\footnotetext{
${ }^{5}$ The classification is available at this link.

${ }^{6}$ All FIRs that are registered under the Indian Penal Code (IPC) sections 302-316, 396, 376, 511, 325, 326, $337,338,279,354,363,364,365,366,397,498$, and 509 are considered to be resulting from the violent crimes. All FIRs that are registered under the IPC sections 231-235, 237-240, 242-243, 255, 364, 370, 372, 373, 379-382, 384-389, 392-394, 397, 398, 395, 399, 402, 420, 435-436, 438, 453-460, 380, 465, 468, 471, and 489 are considered to be resulting from the property crimes.
} 
this information on the number of complaints received by NCW at a monthly level, we create a district panel for the number of complaints received by NCW at a monthly level. We restrict our analysis to the districts in the state of Bihar. We use this data from 2015 to 2019.

We present the distribution of the number of complaints received by NCW from Bihar in Figure 7. Both yearly and monthly distribution show that there is substantial variation in the number of complaints received by the NCW from Bihar. In our empirical strategy, we exploit this temporal variation to uncover the impact of increased ambient air pollution exposure on the number of complaints that the NCW receives.

\subsubsection{Daily NCW Complaints Data}

NCW also reports data on the number of complaints it receives on the violence against women daily. This data, however, is district de-identified. We use the daily data on the number of complaints received by NCW to construct a daily panel on the number of complaints received by NCW for the entire country. We use daily data on the number of complaints received by the NCW from 2015 to 2019.

\subsection{Air Pollution}

We use EAC4 (ECMWF Atmospheric Composition Reanalysis 4) global reanalysis of atmospheric composition data on PM2.5 as our measure of air pollution. Reanalysis combines model data with observations from across the world into a globally complete and consistent dataset using a model of the atmosphere based on the laws of physics and chemistry (Inness et al. (2019), Pullabhotla (2018), and Singh (2020)). These data are available at a very high resolution of $0.01^{\circ} \times 0.01^{\circ}$ every three hours. This approximately corresponds to the data at a $1 \mathrm{~km} \times 1 \mathrm{~km}$ grid.

Satellite data is shown to be highly effective in measuring the extent of ambient air pollution. In areas with a poor spatial and temporal resolution of pollution measures, such as the area in our study, satellite data on air pollution is a good proxy for ambient air pollution (Chowdhury et al. (2019)). Increasingly economists are using satellite data to overcome the problem of low and variable spatial and temporal coverage of groundbased measurement of ambient air pollution (Bombardini \& Li (2020), Burgess et al. (2012), Currie et al. (2020), and Jayachandran (2009)). Although there are more than seventy ground-based monitoring stations in Bihar, not all measure PM2.5 concentration. More- 
over, a large number of these monitors are available only in urban areas. Further, there is also a concern relating to the selection of locations for ground-based pollution monitors. Recent work has shown that often these monitors are located in locations that have low pollution concentrations and have missing readings during periods of elevated pollution levels (Grainger et al. (2018), and Zou (Forthcoming)).

To create the measure of PM2.5 concentration for each police station in our data, we use the police station's geolocation information. We extract each police station's geographical coordinates in our sample using the Google Maps API service. We then use this information to create an inverse distance weighted (IDW) average of all the PM2.5 concentration measures within a radius of $50 \mathrm{~km}$ around each police station. IDW average PM2.5 concentration is computed for each three-hour interval for each day in our sample. We then create a daily average PM2.5 concentration by taking a simple average of all the IDW average three hourly measures during the day. This gives us a daily panel of PM2.5 concentrations for each police station in our sample. In robustness checks, we also present results when the radius around the police station over which we compute the PM2.5 concentration is $40 \mathrm{~km}$ and $75 \mathrm{~km}$ instead of $50 \mathrm{~km}$.

To create the measure of PM2.5 concentration for each district of Bihar, we use the district centroid geolocation information. In an analogous way as for police station level measure of PM2.5 concentration, we construct a daily panel of PM2.5 concentration for each district in our sample. To construct the country measure of PM2.5 concentration, we use all the PM2.5 measures that lie within the country's geographical extent and follow an analogous strategy as above to get a daily panel of PM2.5 concentration for the entire country.

We present the descriptive statistics on PM2.5 concentration in our sample in Table 1. The average daily $P M 2.5$ concentration in our sample is approximately $150 \mu \mathrm{g} / \mathrm{m}^{3}$. This is significantly higher than the average daily concentration that is deemed to be satisfactory as per the World Health Organization (WHO) $-25 \mu \mathrm{g} / \mathrm{m}^{3}$. This is in line with the other studies that find that air quality in India's northern states is very bad (Guo et al. (2019)).

We also show temporal variation in average daily PM2.5 concentration in Figure 8, Figure 9, and Figure 10. Figure 9 show the monthly average daily PM2.5 concentration for our sample. We see that our PM2.5 measure correlates well with findings from other studies and anecdotal evidence. The pollution is significantly higher during the winter months, from November to February. In contrast, the monsoon season from June to September see better air quality. This also shows seasonality in the pollution, and it is 
important to control for weather conditions that can potentially impact the ambient air pollution levels.

\subsection{Weather}

We use weather data from the ERA5-Land hourly dataset. ERA5-Land is a reanalysis dataset providing a consistent view of land variables' evolution over several decades. Reanalysis produces data that goes several decades back in time, providing an accurate description of the past climate. ERA-5 satellite data on climatic conditions is found to be highly correlated and is considered a good proxy for surface climatic conditions (Dell et al. (2014), Hersbach et al. (Forthcoming), Pullabhotla (2018), and Zandler et al. (2020)).

This data is available every hour at a spatial resolution of $0.1^{\circ} \times 0.1^{\circ}$. We use data on weather conditions that might impact criminal activity. Specifically, we use data on cumulative precipitation, temperature, wind speed, dew point (a measure of humidity), and atmospheric pressure.

We use the data from the nearest grid point to each police station in Bihar to get data on the weather covariates corresponding to each police station. We use data from the nearest grid point to each district's centroid to get data on the weather covariates corresponding to each district in Bihar. For our analysis using the daily data on the number of complaints received by the NCW for the entire country, we use all the grid points for the country. In order to construct daily measures of weather covariates, we take a simple average of each hourly reading for each weather covariate for each day in our sample. Following Deryugina et al. (2019), we control for weather conditions non-parametrically. For each weather covariate, we generate indicators for the variable falling in one of four quartiles of the overall distribution over the sample period. This allows us to control for the potential non-linear relationship between weather and criminal activity. Table 1 presents basic descriptive statistics for each of the weather covariate that we use in our econometric specification.

\section{Estimation Strategy}

We use fixed effects regression to causally identify the impact of air pollution on criminal activity. We estimate the following equation for our police station level analysis: 


$$
\mathrm{FIR}_{\mathrm{it}}=\beta \mathrm{PM} 2.5_{\mathrm{it}}+\gamma \mathrm{W}_{\mathrm{it}}+\alpha_{\mathrm{i}}+\delta_{\mathrm{t}}+\epsilon_{\mathrm{it}}
$$

where $i$ either refers to the police station or the police district. FIR $R_{i t}$ refers to the number of FIRs registered at the police station or police district $i$ on date $t$. PM2.5 it is the measure of PM2.5 concentration at police station or police district $i$ on date $t$. $W_{i t}$ is a vector of weather controls that might jointly affect the criminal and the concentration of PM2.5. Following Deryugina et al. (2019), we control for these weather conditions nonparametrically. For each weather variable, we generate indicators for the variable falling in one of four quartiles of the sample distribution. Weather controls contain cumulative precipitation, temperature, dew point temperature, sea level pressure, and wind speed. This allows us to control for the potential non-linear relationship between weather and criminal activity. $\alpha_{i}$ are cross-section fixed effects that control for any time-invariant crosssection characteristics. For police station-level analysis, these refer to police station fixed effects. For police district-level analysis, these refer to police district fixed effects. $\delta_{t}$ are time fixed effects that control for secular changes in criminal activity and air pollution. These time-fixed effects include year, month, calendar week, and day of week fixed effects. ${ }^{7} \epsilon_{\text {it }}$ is the idiosyncratic error term which we cluster either at the police station level or police district level (Abadie et al. (2017), and Cameron \& Miller (2015)). Our coefficient of interest is $\beta$.

While using the district-identified monthly data on the number of complaints received by NCW, we estimate a variant of the equation (2). Our cross-section unit is the district in the state of Bihar. We include district and time fixed effects. While controlling for time fixed effects, we include year and month fixed effects to capture the secular change in complaints received by NCW.

For the country analysis, while using the district de-identified daily data on the number of complaints received by the NCW, we estimate the following equation:

$$
Y_{t}=\beta P M 2.5_{t}+\gamma W_{t}+\delta_{t}+\epsilon_{t}
$$

where $Y_{t}$ refers to the number of complaints received by the NCW on date t. PM2.5t is the PM2.5 concentration on date $t$. All other parameters are identical to the parameters in equation (2).

Due to count nature of our data, in addition to the OLS estimation, we also employ

\footnotetext{
${ }^{7}$ We control for calendar week and day of week fixed effects at the same time as controlling for both of them at the same time results in very similar point estimates than we control for only one of them.
} 
Poisson Pseudo Maximum Likelihood estimation (Correia et al. (2019b), Correia et al. (2019a), and Santos Silva \& Tenreyro (2011)).

In order to interpret our estimates as causal effects, the identifying assumption that must be satisfied is that after controlling for weather covariates and fixed-effects, there are no unobservables correlated with ambient air pollution and criminal activity. In order to circumvent the issues arising due to the possible endogeneity of the PM2.5 concentration measure, we use an instrumental variables strategy exploiting plausibly exogenous local variation in wind directions. Our IV strategy is closely related to Deryugina et al. (2019). Depending upon the relative location of the pollutant sources, a particular police station might be more or less exposed to air pollution. This emanates from the ability of the pollutants to be transported in ambient air over long distances.

We use the wind direction information at the nearest grid-point to each police station to assign the wind direction to the police station. We transform the wind direction to be in one of the eight wind direction bins $b$ based on the octant from which the wind blows from. Our instrumental variable is a series of binary indicators resulting from the interaction of eight wind direction bins $b$ and a binary indicator for police station $i$ to be in administrative division $d$. In Bihar, there are nine administrative divisions in total. We use wind from the east as the base or omitted category. Thus we have $(B-1) \times D=$ $7 \times 9=63$ indicator variables that we use as instruments for PM2.5 $5_{i t}$. Hence, the first stage regression equation is :

$$
\text { PM2.5 } 5_{i t}=\sum_{d=1}^{D} \sum_{b=1}^{B} \zeta^{d, b} \mathbf{1}\left(\text { WindDir }_{i t}=b\right) \times \mathbf{1}\left(\text { Division }_{i}=d\right)+\gamma W_{i t}+\alpha_{i}+\delta_{t}+\epsilon_{p t}
$$

where all parameters are identical to equation (2). For the wind direction IV to be valid, the relevant exclusion restriction that must be satisfied is that there are no omitted variables correlated with both the wind-direction and crime, after controlling for weather covariates and fixed effects.

This specification apriori allows us to make no assumption about which direction is responsible for pollution in a given administrative division, as this is determined by relative locations of pollutant sources. The variation in the instrument that we exploit is summarized in Figure 12. The effects of the same wind direction on ambient air pollution are heterogeneous across locations. For instance, wind from the north has a strong negative effect on PM2.5 concentration in the administrative division of Purnia and Kosi as it 
carries relatively clean air from the Himalayas. The same wind from the north, however, increases PM2.5 concentration in the administrative division of Patna as the pollutants from various inland sources are transported downwind.

\section{Results}

\subsection{Main Results}

We start by presenting the relationship between the number of FIRs registered at the police station and PM2.5 concentration in Figure 2. We plot the residual number of FIRs registered against residual PM2.5 concentration after controlling for meteorological factors and the full set of fixed effects as defined in equation (2). In Panel 2a we present residuals for all the crimes registered at the police station. Panel $2 \mathrm{~b}$ and Panel $2 \mathrm{c}$ present residuals for the crimes that are registered under IPC pertaining to violent crimes and property crimes, respectively. All three panels show a strong negative correlation between PM2.5 concentration and criminal activity as measured by the number of FIRs registered at the police station. We also present results from IV estimation, where the PM2.5 concentration is instrumented by local variation in wind direction in a way outlined in equation (4). We present the relationship between criminal activity and ambient air pollution using this strategy in Figure 3. We continue to find that elevated levels of PM2.5 concentration have a negative effect on criminal activity.

We now discuss results from estimating specification in equation (2). These results are presented in Table 2. The first six columns are for the police station panel, and the following six columns are for the police district panel. We first discuss results from the police station panel. The point estimate of -0.021 in column (1) means that an increase of one standard deviation in $P M 2.5$ concentration $\left(S D=96.04 \mu \mathrm{g} / \mathrm{m}^{3}\right)$ is associated with a decrease of 0.021 FIRs being registered for all crimes or $5.29 \%$ of the average rate $(0.397)$. To put this into perspective, our point estimate suggests that $P M 2.5$ concentration above the World Health Organization (WHO) safe limits on a given day in our sample on an average reduces the number of crimes registered approximately by 0.027 , or $6.94 \%$ of the 
sample average. ${ }^{8,9}$ Column (3) and column (5) of Table 2 present results from estimating equation (2) for crimes that are registered under the sections of the IPC that pertain to violent crimes and property crimes, respectively. Both these point estimates are negative and highly statistically significant. Reduction in the criminal activity suggested by these point estimates is higher for property crimes than for violent crimes. Our point estimates are highly statistically significant even when we account for spatial correlation in the PM2.5 concentration measure.

We next discuss results from our IV specification where we instrument for PM2.5 concentration using the local variations in the wind direction in a manner described in equation (4). Column (2) of Table 2 presents results from IV estimation for FIRs registered for all crimes. The point estimate of -0.031 in column (2) implies that an increase of one standard deviation in PM2.5 concentration (SD $\left.=96.04 \mu \mathrm{g} / \mathrm{m}^{3}\right)$ is associated with a decrease of 0.031 FIRs being registered for all crimes or $7.81 \%$ of the average rate $(0.397)$. This point estimate suggests that PM2.5 concentration above the World Health Organization (WHO) safe limits on a given day in our sample on an average reduces the number of crimes registered approximately by 0.041 , or $10.91 \%$ of the sample average. Column (4) and column (6) of Table 2 present results from IV estimation for crimes that are registered under the sections of the IPC that pertain to violent crimes and property crimes, respectively. Both these point estimates are negative and highly statistically significant. Our point estimates from IV estimation are slightly higher than those from OLS estimation. First stage $F$-statistics that we report in all our IV estimation suggest that our instrument is highly correlated with the PM2.5 concentration.

We next discuss results from using the police district panel instead of the police station panel. These results are presented in the last six columns of Table 2. As discussed above, estimation is slightly different from the estimation using the police station panel. Specifically, we aggregate the crimes registered in all the police stations of the police district under which the given police station comes. All point estimates are negative and highly statistically significant. The pattern observed above of air pollution has a larger

\footnotetext{
${ }^{8}$ WHO suggests the average 24-hour concentration to be safe if it is not greater than $25 \mu \mathrm{g} / \mathrm{m}^{3}$. The average 24-hour concentration of PM2.5 in our sample is 150.36. Taking the product of the difference of the average 24-hour concentration of PM2.5 and the WHO safe limit with the estimated effect of ambient PM2.5 concentration on the number of FIRs registered $(-0.021 / 96.04)$ gives us the average reduction of 0.027 crimes registered in Bihar.

${ }^{9}$ Daily average number of FIRs on all crimes registered in our sample are 0.397. Taking the ratio of the estimated reduction in the daily crimes by virtue of the ambient PM2.5 concentration to be above the limits considered safe $(0.027)$ and the daily average number of FIRs registered gives us the reduction of $6.94 \%$ in the registered crimes in Bihar.
} 
negative impact on property crimes than violent crimes for police station panel continue to hold. Apart from estimating the effect of ambient air pollution on criminal activity over a larger geographical region, these results also help us alleviate concerns related to the aggregation of crimes registered at the police station.

\subsection{Robustness Checks}

Due to the count nature of the FIR data, we also present results from using the Poisson Pseudo Maximum Likelihood Estimator (PPML). Specifically, we estimate the specification in equation (2) using PPML for both the police station panel and police district panel. We present the results in Table 3. We see that all the six-point estimates are of the same sign as in Table 2 and continue to be highly statistically significant. Further, the point estimates from the PPML estimator are larger in magnitude than the point estimates from OLS. This gives us confidence that the results presented in section (6.1) are not driven by choice of estimator.

We next discuss robustness of our main results in section (6.1) to addition of fixed effects to our main specifications in equation (2). We present results from augmenting our baseline specifications with more fixed effects in equation (2) both for police station panel and police district panel. Police station panel results are presented in Table 6 and police district panel results are presented in Table 7. Results in Table 6 and Table 7 show that alternate fixed effects specifications do not alter our main result of higher levels of ambient air pollution being associated with lower criminal activity. Further, a relatively larger effect of ambient air pollution on the criminal activity for property crimes than for violent crimes is seen even when we employ different fixed effects in our main specification. This allows us to conclude that our main results are not altered by the specific fixed effects specification we employ in equation (2).

To establish the robustness of our results to the specific choice of the radius around the police station over which we construct our measure of PM2.5 concentration, we now present results from estimating equation (2) with alternate choices of the radius. We present these results in Table 8 and Table 9 for police station panel and police district panel, respectively. We present results from two alternate choices of radius $-40 \mathrm{~km}$ and $75 \mathrm{~km}$. The results from estimation of equation (2) suggest that our point estimates from the main results presented in Table 2 are similar to the point estimates in Table Table 8 and Table 9. These results show that our main results are robust to the specific choice of the radius around the police station over which we construct our measure of ambient air 
pollution.

To further alleviate the concerns regarding the possible under-reporting of criminal activity in the registered FIR data, we now discuss results from the publicly available data from NCW. We use two publicly available datasets -monthly complaints data and daily complaints data-from NCW. Both of these are discussed in more detail in section (4.1.2) and section (4.1.3), respectively.

We first discuss results from estimating a variant of equation (2) using the monthly complaints data from NCW. We present the results from this estimation in Table 4. Column (1) presents results from the OLS estimation. Column (2) considers the count nature of the complaints data and employs a PPML estimator. The results in both the column show that a higher level of average monthly PM2.5 concentration in the district leads to a reduction in the number of complaints received by NCW in that month. Although of the same sign as that of the point estimates from our main results, these estimates are not statistically significant.

We next discuss results from estimating equation (3) using the daily complaints data from NCW. We present these results in Table 4. Column (3) presents results from the OLS estimation. Column (4) takes into account the count nature of the complaints data and employs a PPML estimator. The results in both columns suggest that higher levels of ambient air pollution lead to lower complaints being received by the NCW. Similar to the monthly NCW data results, these point estimates are of the same sign as that of the point estimates from our main results but continue to be statistically insignificant.

We next discuss results from estimating equation (2) where we drop one year from our data at a time. This robustness check will allow us to shed some light on whether a particular year is contributing to our results in the section (6.1) or not. We present the results from this exercise in Figure 4 for OLS estimation and Figure 5 for IV estimation. We present results for both the police station panel and police district panel. The results suggest that even after we account for differential contribution by years, our results are similar to what we find in section (6.1). This allows us to conclude that our results are not being driven by a particular year that we analyze in our sample.

For a sub-sample of our FIRs, we also have information on the date of the incident. We next show that our results are robust to using the date of the incident instead of the date of FIR registration. We present these results in Table 11. We find that the point estimates in Table 11 are very similar to point estimates in Table 2 . This further gives us confidence that our main results are not an artifact of lesser crimes being registered on more polluted 
days.

The results presented in this section lend credence to the findings in section (6.1). We establish the robustness of our main result to the alternate estimator, alternate specifications, alternate radius over which we construct our measure of the ambient air pollution, alternate data sources, sub-sample of years, and using the date of the incident instead of the date of registration of FIR.

\subsection{Survey Data Results}

One possible concern with the FIR and the NCW data that we use in section (6.1) is that it might be prone to reporting bias. To alleviate such concerns, we use the latest available rounds of the Demographic and Health Survey (DHS) 2015-16 and India Human Development Survey (IHDS) 2011-12. We describe these data and the empirical strategy to study criminal activity below.

\subsubsection{Demographic and Health Survey 2015-16}

We make use of the latest available survey round of DHS for India DHS 2015-16. We restrict our sample to the districts in the state of Bihar. Using the information on domestic violence, we construct our measure of domestic violence exposure. We restrict the sample to women who were interviewed for the domestic violence module. We make use of questions relating to physical, emotional, and sexual violence to construct an indicator variable for whether the respondent reported any acts of domestic violence in the last twelve months. Additionally, we also look at the incidence of physical and emotional violence separately. ${ }^{10}$

We use the geo-code information on the DHS clusters to construct our measure of PM2.5 concentration. We take a radius of $20 \mathrm{~km}$ around each DHS cluster location and construct an inverse distance weighted measure of the air pollution by using all the grid points that fall within this radius. We then assign this pollution measure to each household that belongs to the cluster. Since our dependent variable relates to the acts of domestic violence in the last twelve months, we make use of the date on which the household was interviewed and take the reference period to be all the days from one year preceding the date of the interview to the interview date to construct pollution measure and weather

\footnotetext{
${ }^{10}$ While looking at the incidence of different types of violence separately, we club physical violence and sexual violence together. Thus, a woman is said to have reported an act of physical violence in the last twelve months if she reported any act of physical violence or sexual violence over the same period.
} 
covariates. Thus, if the household was interviewed on January 1st, 2016, then the reference period for the pollution measure and the weather covariates is from January 1st, 2015 to January 1st, 2016. While constructing the measures for pollution and weather covariates, we take an average of all the observations within this one-year window. To protect the identity of the respondent, DHS cluster locations are randomly displaced by up to 5 $\mathrm{km}$, with $1 \%$ of the clusters displaced up to $10 \mathrm{~km}$. Since we take a radius larger than 10 $\mathrm{km}$ to construct our measure of PM2.5 concentration, we take this random displacement of DHS clusters into account.

To study the effect of exposure to air pollution on domestic violence, we estimate the following regression specification.

$$
Y_{i}=\beta P M 2.5_{j(i) t(i)}+\gamma W_{j(i) t(i)}+\delta X_{h(i)}+\zeta_{d(i)}+\eta_{t(i)}+\epsilon_{i}
$$

where $j(i)$ is the cluster in which the household in which the woman $i$ reside belongs and $Y_{i}$ is the outcome of interest. For the DHS data, $Y_{i}$ is an indicator variable for whether the woman in the household $h(i)$ in cluster $j(i)$ who was interviewed on date $t(i)$ reported any acts of domestic violence in the last twelve months. We also look at two other outcomes-whether the woman reported any acts of physical violence in the last twelve months and whether the woman reported any acts of emotional violence in the last twelve months. PM $2.5_{j(i) t(i)}$ is the mean PM2.5 concentration in the twelve months preceding the date of interview $t(i) . W_{j(i) t(i)}$ is a set of weather covariates where each of the covariates is the mean in the twelve months preceding the date of the interview. We use the same set of weather covariates that we used in the equation (2). $X_{h(i)}$ is the set of householdlevel characteristics. These include the highest education level in the household, religion, number of members in the household, and the wealth index. $\zeta_{d(i)}$ is the set of district fixed effects. $\eta_{t(i)}$ is the set of year fixed effects. $\epsilon_{i}$ is the idiosyncratic error term which we cluster at the district level (Abadie et al. (2017) and Cameron \& Miller (2015)).

We present the results from the estimation of equation (5) in Table 5. For the incidence of any act of domestic violence in the last twelve months, our point estimate is positive but statistically insignificant at conventional levels of statistical significance. While looking at physical and emotional violence separately, we find a similar effect on violence incidence due to exposure to higher ambient air pollution levels. Although these results are statistically insignificant, they can help us study the underlying channels that lead to the main results. We discuss this in more detail in section (6.4). 


\subsubsection{India Human Development Survey 2011-12}

To further alleviate concerns regarding the reporting bias in the data used for the main results, we use the latest IHDS survey round from 2011-12 to see how criminal activity is impacted by exposure to air pollution. We restrict the sample to the districts in the state of Bihar. We use information in the IHDS survey that pertains to the local criminal activity. We use the questions that relate to the property crimes and violent crimes in the last twelve months as reported by the respondent. We construct an indicator for whether the respondent reported any criminal activity in the neighborhood in the last twelve months. ${ }^{11}$ The nature of the questions also allows us to shed light on how property and violent crimes are affected due to exposure to higher ambient air pollution levels.

Using the information on the district in which the interviewed household is located with the information on the district centroids' geo-coordinates using the census 2001 shapefiles, we construct a measure of PM2.5 concentration in the last twelve months for each household. We take a radius of $50 \mathrm{~km}$ around each district centroid and construct an inverse distance weighted measure of the air pollution by using all the grid points within this radius. We then assign this pollution measure to each household that belongs to the district. Since our dependent variable relates to the acts of crimes in the last twelve months, we make use of the date on which the household was interviewed and take the reference period to be all the days from one year preceding the date of the interview to the interview date to construct pollution measure and weather covariates. Thus, if the household was interviewed on January 1st, 2012, then the reference period for the pollution and the weather variables is from January 1st, 2011 to January 1st, 2012. While constructing the measures for pollution and weather covariates, we take an average of all the observations within this one-year window.

To study the effect of exposure to air pollution on neighborhood criminal activity, we estimate a variant of the specification in equation (5). Instead of $j(i)$ being the cluster in which the household in which woman $i$ was interviewed falls, $j(i)$ now refers to the district in which the household in which woman $i$ was interviewed falls in. The rest of the parameters are identical to those in the equation (5). As described above, the outcomes of interest, in this case, are those related to the incidence of local crimes.

\footnotetext{
${ }^{11}$ Specific questions that relate to local crimes that we use to construct our measure are - (1) "During the last twelve months, was anything stolen that belonged to you or to somebody in your household?", (2) "During the last twelve months, did anyone break into your home or illegally get into your home?", (3) "During the last twelve months, did anyone attack or threaten you or someone in your household?", and (4) "How often are unmarried girls harassed in your village/urban neighborhood?"
} 
We present the results from the estimation of equation (5) in Table 5. We look at both the overall criminal activity and criminal activity pertaining to property and violent crimes separately. Results for the neighborhood's overall criminal activity are presented in the fourth column. The point estimate is of the same sign as our main results but is not statistically significant. When we look at property crimes and violent crimes separately, we see that the point estimates are negative for both, but statistical significance is obtained only in the case of violent crimes. The point estimate of -0.196 means that an increase of one standard deviation in $P M 2.5$ concentration $\left(\mathrm{SD}=20.76 \mu \mathrm{g} / \mathrm{m}^{3}\right)$ is associated with a decrease of 0.196 violent crimes in the neighborhood, or $1300 \%$ of the average rate (0.015). ${ }^{12}$ We also present results for each of the four individual questions relating to the local crime that the respondent was asked. The last four columns of Table 5 present these results. We find that there is a statistically significant negative effect of elevated ambient air pollution levels on crimes related to burglary or theft.

Our results in the section (6.3) confirm findings from our main results in section (6.1). Thus, we conclude that our main results are not driven by the specific nature of the data that we use to uncover the effects of ambient air pollution on criminal activity.

Although the results presented above help in ameliorating concerns related to the reporting bias in the main results, we should be careful in comparing these with the results in section (6.1). This is primarily because the temporal frequency varies in the two settings. While we use a high-frequency daily panel on criminal activity and pollution exposure for our main results, this section uses a longer time horizon as far as the pollution exposure is concerned. Thus, this section's results should be interpreted with some caution and should be understood as the medium-term effects of exposure to air pollution on criminal activity.

\subsection{Probing Mechanisms}

Utilizing detailed data on the nature of crimes, we can probe mechanisms that might lead to observed results. In what follows, we look at whether the crimes that are unlikely to be impacted by the reduced potential victims are affected by the change in ambient air pollution. Suppose we expect people to shield and reduce their exposure to elevated levels of ambient air pollution, increasing the costs of indulging in criminal activity. In that case, we should not see an impact on such crimes.

\footnotetext{
${ }^{12}$ This translates to a decrease of $62.94 \%$ of the average rate due to an increase of $1 \mu \mathrm{g} / \mathrm{m}^{3}$ in $P M 2.5$ concentration.
} 
We present results from the estimation of equation (2) for crimes that are unlikely to be impacted by the change in ambient air pollution levels in Table 10. Specific crimes that we look at are counterfeit crimes, foreign importation crimes, and cybercrimes. We also look at the incidence of any of these three crimes. The results for both the police station level panel and police district panel show that changes in ambient air pollution have no impact on crimes unlikely to be impacted due to reduced outdoor activities by the potential victims.

To further appeal to this channel, we can look at what happens to property crimes and domestic violence in the presence of elevated levels of ambient air pollution. Suppose it is the case that on days of relatively high air pollution, people stay indoors. In that case, we should see a decline in the property crimes like burglary and theft. Column (5) and column (6) of Table 2 show that the negative impact of elevated air pollution levels is relatively higher for property crimes than for violent crimes. Further, point estimates column (6) and column (8), where the latter shows changes in someone breaking into the house in Table 5 suggest that property crimes appear to be negatively associated with higher ambient air pollution. While looking at the incidence of domestic violence, the first three columns of Table 5 show that a higher level of PM2.5 concentration in the year preceding the interview date is positively associated with reporting an incidence of domestic violence, albeit statistically insignificantly. These three results lend credence to the hypothesis that elevated air pollution levels increase the costs of indulging in criminal activity.

Finally, to rule out the channel of a higher likelihood of committing a crime that might result from lower deterrence on the part of the police force, we show how the arrests behave on days of high air pollution. Suppose we believe that arrests reflect the effort exerted by the police force to deter crimes. In that case, lower arrests due to elevated air pollution levels can reflect a lower effort by the police on high pollution days. We estimate the specification in equation (2) where the dependent variable is the number of arrests made at the police station or in the police district. All the other parameters remain the same. We present results from this estimation in Table 12. We find no effect of elevated air pollution levels on the number of arrests made by the police at the police station level and in the police district.

This section shows that the observed negative association between the higher ambient air pollution and criminal activity might be resulting due to increased costs of indulging in criminal activity on such days. Further, we can rule out the decline in effort exerted by 
the police on days of high air pollution by showing that arrests do not respond to changes in the ambient air pollution levels.

\section{Conclusion}

Using high-frequency data on the number of complaints received at each police station in the districts of Bihar, we show that an increase in air pollution reduces criminal activity. Our results show that the decline in criminal activity due to elevated air pollution levels occurs for both property crimes and violent crimes, but the effect is more pronounced for property crimes. Our results are robust to a host of robustness checks. We show that our findings are also not altered when we account for potential reporting bias in our main data source by using alternate survey data. Exploring the potential channels that might help explain our findings, we show that the decline in criminal activity could be due to increased costs of indulging in crime on more polluted days. Further, using novel data on the number of arrests made at each police station, we are able to rule out the channel of reduced effort exerted by the police on days of high ambient air pollution. Our results have important implications for policy research as we show that it is crucial to fully account for the benefits and costs of high levels of air pollution. We show that there could be some unintended benefits of exposure to bad air quality in addition to enormous health costs imposed by high pollution levels. 


\section{References}

Abadie, Alberto, Athey, Susan, Imbens, Guido W, \& WoOldridge, Jeffrey. 2017. When Should You Adjust Standard Errors for Clustering? NBER Working Paper No. 24003.

Anderson, Michael L. 2019. As the Wind Blows: The Effects of Long-Term Exposure to Air Pollution on Mortality. Journal of the European Economic Association, 18(4), 18861927.

Aragón, Fernando M., Miranda, Juan Jose, \& Oliva, Paulina. 2017. Particulate matter and labor supply: The role of caregiving and non-linearities. Journal of Environmental Economics and Management, 86, 295 - 309.

Arceo, Eva, Hanna, Rema, \& Oliva, Paulina. 2016. Does the Effect of Pollution on Infant Mortality Differ Between Developing and Developed Countries? Evidence from Mexico City. The Economic Journal, 126(591), 257-280.

Austin, Wes, Heutel, Garth, \& Kreisman, Daniel. 2019. School bus emissions, student health and academic performance. Economics of Education Review, 70, 109 - 126.

Barrios, Thomas, Diamond, Rebecca, imbens, Guido W., \& Kolesár, Michal. 2012. Clustering, Spatial Correlations, and Randomization Inference. Journal of the American Statistical Association, 107(498), 578-591.

BeAtTy, Timothy K.M., \& ShimshacK, JAy P. 2011. School buses, diesel emissions, and respiratory health. Journal of Health Economics, 30(5), 987 - 999.

Becker, Gary S. 1968. Crime and Punishment: An Economic Approach. Journal of Political Economy, 76(2), 169-217.

Bharadwaj, Prashant, Gibson, Matthew, Zivin, Joshua Graff, \& Neilson, Christopher. 2017. Gray Matters: Fetal Pollution Exposure and Human Capital Formation. Journal of the Association of Environmental and Resource Economists, 4(2), 505-542.

Bombardini, MatiLde, \& LI, BingJiNG. 2020. Trade, pollution and mortality in China. Journal of International Economics, 125, 103321.

Bondy, Malvina, Roth, Sefi, \& Sager, Lutz. 2020. Crime Is in the Air: The Contemporaneous Relationship between Air Pollution and Crime. Journal of the Association of Environmental and Resource Economists, 7(3), 555-585.

Burgess, Robin, Hansen, Matthew, Olken, Benjamin A., Potapov, Peter, \& Sieber, Stefanie. 2012. The Political Economy of Deforestation in the Tropics. The 
Quarterly Journal of Economics, 127(4), 1707-1754.

Burke, Marshall B., Miguel, Edward, Satyanath, Shanker, Dykema, John A., \& LOBELL, DAVID B. 2009. Warming increases the risk of civil war in Africa. Proceedings of the National Academy of Sciences, 106(49), 20670-20674.

Burkhardt, Jesse, Bayham, Jude, Wilson, Ander, Carter, Ellison, Berman, Jesse D., O’Dell, Katelyn, Ford, Bonne, Fischer, Emily V., \& Pierce, JefFREY R. 2019. The effect of pollution on crime: Evidence from data on particulate matter and ozone. Journal of Environmental Economics and Management, 98, 102267.

Cameron, Colin A., \& Miller, Douglas L. 2015. A Practitioner's Guide to ClusterRobust Inference. Journal of Human Resources, 50(2), 317-372.

Chang, Tom, Graff Zivin, Joshua, Gross, Tal, \& Neidell, Matthew. 2016. Particulate Pollution and the Productivity of Pear Packers. American Economic Journal: Economic Policy, 8(3), 141-69.

Chay, Kenneth Y., \& Greenstone, Michael. 2003. The Impact of Air Pollution on Infant Mortality: Evidence from Geographic Variation in Pollution Shocks Induced by a Recession. The Quarterly Journal of Economics, 118(3), 1121-1167.

Chen, Shuai, Oliva, Paulina, \& Zhang, Peng. 2018. Air Pollution and Mental Health: Evidence from China. NBER Working Paper No. 24686.

CHOWdhury, SOURANGSu, \& DeY, SAGNIK. 2016. Cause-specific premature death from ambient PM2.5 exposure in India: Estimate adjusted for baseline mortality. Environment International, 91, $283-290$.

Chowdhury, Sourangsu, Dey, Sagnik, Di Girolamo, Larry, Smith, Kirk R., Pillarisetti, Ajay, \& Lyapustin, AleXei. 2019. Tracking ambient PM2.5 buildup in Delhi national capital region during the dry season over 15 years using a highresolution $(1 \mathrm{~km})$ satellite aerosol dataset. Atmospheric Environment, 204, 142 - 150.

Correia, Sergio, Guimarães, Paulo, \& Zylkin, Thomas. 2019a. ppmlhdfe: Fast Poisson Estimation with High-Dimensional Fixed Effects.

Correia, Sergio, Guimarães, Paulo, \& Zylkin, Thomas. 2019b. Verifying the existence of maximum likelihood estimates for generalized linear models.

Currie, Janet, \& Neidell, Matthew. 2005. Air Pollution and Infant Health: What Can We Learn from California's Recent Experience? The Quarterly Journal of Economics, 120(3), 1003-1030.

Currie, JANet, \& WALKer, ReEd. 2011. Traffic Congestion and Infant Health: Evidence 
from E-ZPass. American Economic Journal: Applied Economics, 3(1), 65-90.

Currie, Janet, Neidell, Matthew, \& Schmieder, Johannes F. 2009. Air pollution and infant health: Lessons from New Jersey. Journal of Health Economics, 28(3), 688 703.

Currie, Janet, Greenstone, Michael, \& Moretti, Enrico. 2011. Superfund Cleanups and Infant Health. American Economic Review, 101(3), 435-41.

Currie, Janet, Voorheis, John, \& Walker, Reed. 2020. What Caused Racial Disparities in Particulate Exposure to Fall? New Evidence from the Clean Air Act and Satellite-Based Measures of Air Quality. NBER Working Paper No. 26659.

Dell, Melissa, Jones, Benjamin F., \& Olken, Benjamin A. 2014. What Do We Learn from the Weather? The New Climate-Economy Literature. Journal of Economic Literature, 52(3), 740-98.

Deryugina, Tatyana, Heutel, Garth, Miller, Nolan H., Molitor, David, \& Reif, Julian. 2019. The Mortality and Medical Costs of Air Pollution: Evidence from Changes in Wind Direction. American Economic Review, 109(12), 4178-4219.

Deschenes, Olivier, Wang, Huixia, Wang, Si, \& Zhang, Peng. 2020. The effect of air pollution on body weight and obesity: Evidence from China. Journal of Development Economics, 145, 102461.

Doleac, Jennifer L., \& SAnders, Nicholas J. 2015. Under the Cover of Darkness: How Ambient Light Influences Criminal Activity. The Review of Economics and Statistics, 97(5), 1093-1103.

Ebenstein, Avraham, LaVy, Victor, \& Roth, Sefi. 2016. The Long-Run Economic Consequences of High-Stakes Examinations: Evidence from Transitory Variation in Pollution. American Economic Journal: Applied Economics, 8(4), 36-65.

Fetzer, Thiemo. 2020. Can Workfare Programs Moderate Conflict? Evidence from India. Journal of the European Economic Association, 18(6), 3337-3375.

Ghosh, Arkadipta, \& Mukherji, Arnab. 2014. Air Pollution and Respiratory Ailments among Children in Urban India: Exploring Causality. Economic Development and Cultural Change, 63(1), 191-222.

Ghude, Sachin D., Chate, D. M., Jena, C., Beig, G., Kumar, R., Barth, M. C., Pfister, G. G., Fadnavis, S., \& Pithani, Prakash. 2016. Premature mortality in India due to PM2.5 and ozone exposure. Geophysical Research Letters, 43(9), 4650-4658.

Grainger, Corbett, Schreiber, AndreW, \& Chang, Wonjun. 2018. Do Regulators 
Strategically Avoid Pollution Hotspots when Siting Monitors? Evidence from Remote Sensing of Air Pollution. University of Madison-Wisconsin Working Paper.

Guo, HaO, Kota, Sri Harsha, Sahu, Shovan Kumar, \& Zhang, Hongliang. 2019. Contributions of local and regional sources to PM2.5 and its health effects in north India. Atmospheric Environment, 214, 116867.

Hanna, Rema, \& Oliva, Paulina. 2015. The effect of pollution on labor supply: Evidence from a natural experiment in Mexico City. Journal of Public Economics, 122, 68 79.

Heilmann, Kilian, Kahn, Matthew E., \& Tang, Cheng Keat. 2021. The urban crime and heat gradient in high and low poverty areas. Journal of Public Economics, 197, 104408.

Heissel, Jennifer A., Persico, Claudia, \& Simon, David. 2020. Does Pollution Drive Achievement? The Effect of Traffic Pollution on Academic Performance. Journal of Human Resources.

Herrnstadt, Evan, Heyes, Anthony, Muehlegger, Erich, \& SAberian, SoOdeh. 2020. Air pollution and criminal activity: Microgeographic evidence from Chicago. American Economic Journal: Applied Economics.

Hersbach, Hans, Bell, Bill, Berrisford, Paul, Hirahara, Shoji, Horányi, András, Muñoz-Sabater, Joaquín, Nicolas, Julien, Peubey, Carole, Radu, Raluca, Schepers, Dinand, Simmons, Adrian, Soci, Cornel, Abdalla, Saleh, Abellan, Xavier, Balsamo, Gianpaolo, Bechtold, Peter, Biavati, Gionata, Bidlot, Jean, Bonavita, Massimo, De Chiara, Giovanna, Dahlgren, Per, Dee, Dick, Diamantakis, Michail, Dragani, Rossana, Flemming, Johannes, Forbes, Richard, Fuentes, Manuel, Geer, Alan, HaimBerger, leo, Healy, Sean, Hogan, Robin J., Hólm, Elías, Janisková, Marta, Keeley, Sarah, laloyaux, Patrick, lopez, Philippe, lupu, Cristina, RadNoti, Gabor, de Rosnay, Patricia, Rozum, Iryna, Vamborg, Freja, Villaume, SEbAstien, \& ThÉPAUt, JEAN-NoËL. Forthcoming. The ERA5 global reanalysis. Quarterly Journal of the Royal Meteorological Society.

HSIANG, SOLOMON M. 2010. Temperatures and cyclones strongly associated with economic production in the Caribbean and Central America. Proceedings of the National Academy of Sciences, 107(35), 15367-15372.

Hsiang, Solomon M., Meng, Kyle C., \& Cane, Mark A. 2011. Civil conflicts are 
associated with the global climate. Nature, 476(7361), 438-441.

Hsiang, SOlOMON M., Burke, Marshall, \& Miguel, EdWARD. 2013. Quantifying the Influence of Climate on Human Conflict. Science, 341(6151).

Imbert, Clément, Prakash, Nishith, \& Eynde, Oliver VAnden. 2016. Political change and crime reduction in Bihar.

Inness, A., Ades, M., Agustí-Panareda, A., Barré, J., Benedictow, A., BlechSchmidt, A.-M., DomingueZ, J. J., Engelen, R., Eskes, H., Flemming, J., HuiJnen, V., Jones, L., Kipling, Z., Massart, S., Parrington, M., Peuch, V.-H., Razinger, M., Remy, S., Schulz, M., \& Suttie, M. 2019. The CAMS reanalysis of atmospheric composition. Atmospheric Chemistry and Physics, 19(6), 3515-3556.

Isen, AdAm, Rossin-Slater, Maya, \& WALKer, W. Reed. 2017. Every Breath You Take-Every Dollar You'll Make: The Long-Term Consequences of the Clean Air Act of 1970. Journal of Political Economy, 125(3), 848-902.

IYer, LAKSHMI, \& Topalova, Petia. 2014. Poverty and Crime: Evidence from Rainfall and Trade Shocks in India. Harvard Business School Working Papers.

JACOB, Brian, Lefgren, LARS, \& Moretti, EnRico. 2007. The Dynamics of Criminal Behavior: Evidence from Weather Shocks. Journal of Human Resources, XLII(3), 489-527.

Jans, Jenny, Johansson, Per, \& Nilsson, J. Peter. 2018. Economic status, air quality, and child health: Evidence from inversion episodes. Journal of Health Economics, 61, 220 -232 .

Jayachandran, Seema. 2009. Air Quality and Early-Life Mortality: Evidence from Indonesia's Wildfires. Journal of Human Resources, 44(4), 916-954.

Jia, Beixi, Gao, Meng, Zhang, Xiaorui, XiaO, Xiang, Zhang, Shiqing, \& Lam YUNG, KEN KIN. 2020. Rapid increase in mortality attributable to PM2.5 exposure in India over 1998-2015. Chemosphere, 128715.

KeLly, MORGAN. 2019. The Standard Errors of Persistence.

Marcotte, Dave E. 2017. Something in the air? Air quality and children's educational outcomes. Economics of Education Review, 56, 141 - 151.

Moretti, Enrico, \& Neidell, Matthew. 2011. Pollution, Health, and Avoidance Behavior: Evidence from the Ports of Los Angeles. Journal of Human Resources, 46(1), 154-175.

Neidell, Matthew J. 2004. Air pollution, health, and socio-economic status: the effect of outdoor air quality on childhood asthma. Journal of Health Economics, 23(6), 1209 - 
1236.

Pal, Rupali, Chowdhury, Sourangsu, Dey, SagniK, \& Sharma, Anu Rani. 2018. 18-Year Ambient PM2.5 Exposure and Night Light Trends in Indian Cities: Vulnerability Assessment. Aerosol and Air Quality Research, 18(9), 2332-2342.

Poblete-Cazenave, Ruben. 2020. The Great Lockdown and Criminal ActivityEvidence from Bihar, India. SSRN Working Paper.

Pullabhotla, Hemant K. 2018. Fires, Wind, and Smoke: Air Pollution and Infant Mortality.

Rangel, Marcos A., \& Vogl, TOM S. 2019. Agricultural Fires and Health at Birth. The Review of Economics and Statistics, 101(4), 616-630.

RANSON, MATTHEW. 2014. Crime, weather, and climate change. Journal of Environmental Economics and Management, 67(3), $274-302$.

RAVINDRAN, SARAVANA, \& SHAH, MANISHA. 2020. Unintended Consequences of Lockdowns: COVID-19 and the Shadow Pandemic. NBER Working Paper No. 27562.

Rosales-Rueda, MARIA, \& TriyanA, MARgaret. 2018. The Persistent Effects of EarlyLife Exposure to Air Pollution: Evidence from the Indonesian Forest Fires. Journal of Human Resources.

Sahu, Shovan Kumar, Sharma, Shubham, Zhang, Hongliang, Chejarla, Venkatesh, Guo, HaO, Hu, Jianlin, Ying, Qi, Xing, JiA, \& Kota, Sri Harsha. 2020. Estimating ground level PM2.5 concentrations and associated health risk in India using satellite based AOD and WRF predicted meteorological parameters. Chemosphere, $255,126969$.

SANDERS, Nicholas J. 2012. What Doesn't Kill You Makes You Weaker: Prenatal Pollution Exposure and Educational Outcomes. Journal of Human Resources, 47(3), 826-850.

SAntos Silva, J.M.C., \& TEnREyRO, SilvanA. 2011. Further simulation evidence on the performance of the Poisson pseudo-maximum likelihood estimator. Economics Letters, 112(2), $220-222$.

Schlenker, Wolfram, \& Walker, W. Reed. 2015. Airports, Air Pollution, and Contemporaneous Health. The Review of Economic Studies, 83(2), 768-809.

Singh, Prachi, Dey, SAgniK, ChOWdhury, SOURAngsu, \& BAli, Kunal. 2019. Early Life Exposure to Outdoor Air Pollution.

Singh, Tejendra Pratap. 2020. Beyond The Haze: Air Pollution and Student Absenteeism - Evidence from India. SSRN Working Paper. 
Upadhyay, AbHishek, Dey, SAgnik, Chowdhury, Sourangsu, \& Goyal, Pramila. 2018. Expected health benefits from mitigation of emissions from major anthropogenic PM2.5 sources in India: Statistics at state level. Environmental Pollution, 242, 1817 - 1826.

WARD, COURTNEY J. 2015. It's an ill wind: The effect of fine particulate air pollution on respiratory hospitalizations. Canadian Journal of Economics, 48(5), 1694-1732.

Zandler, Harald, Senftl, Thomas, \& VAnselow, Kim André. 2020. Reanalysis datasets outperform other gridded climate products in vegetation change analysis in peripheral conservation areas of Central Asia. Scientific Reports, 10(1), 22446.

ZOU, ERIC. Forthcoming. Unwatched Pollution: The Effect of Intermittent Monitoring on Air Quality. American Economic Review. 


\section{Figure 1: Police Station Locations}

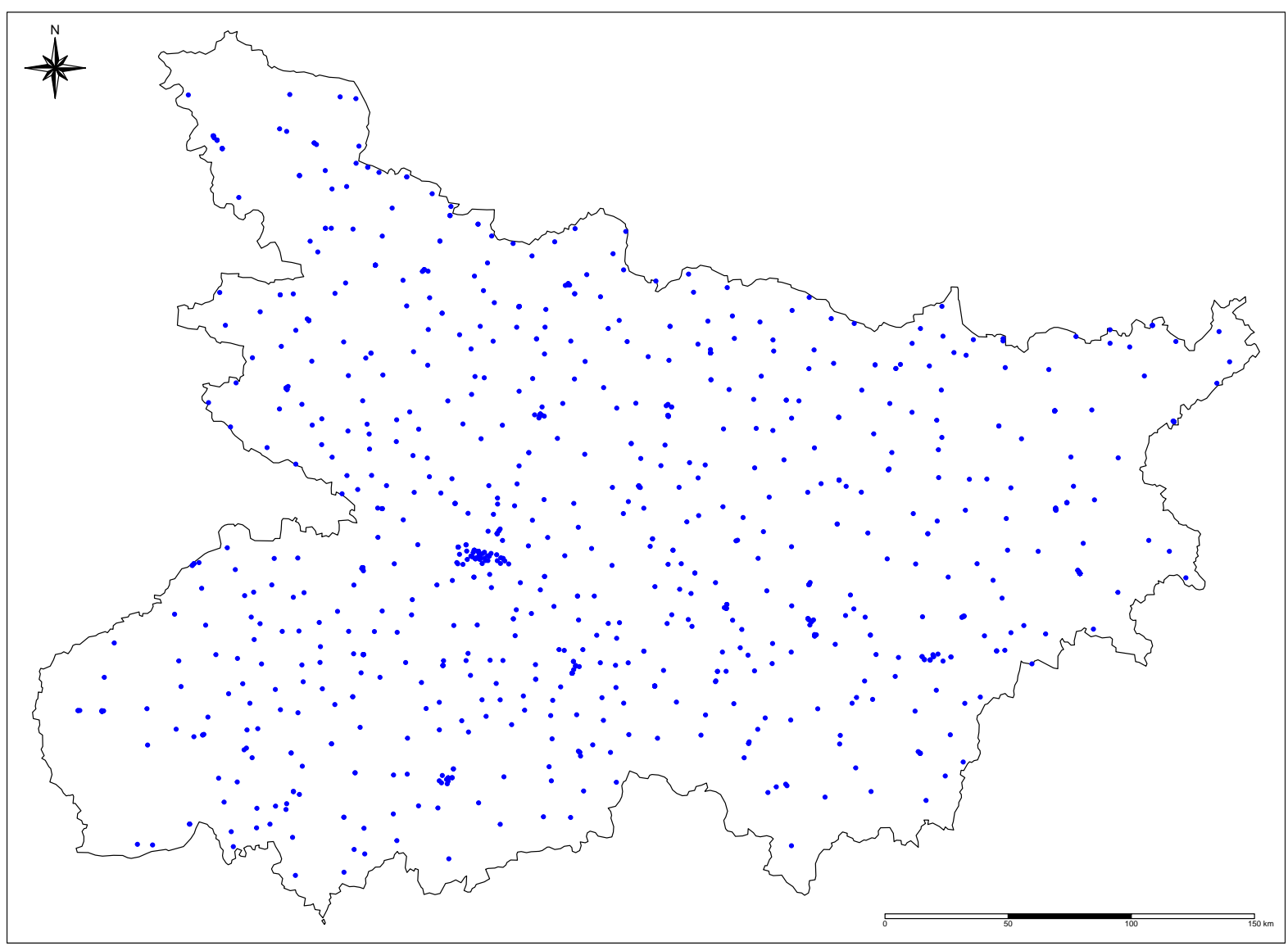

Note: Each dot represents the location of the police station. Police station locations are not publicly available. Google API geo-coding service is used to geo-code the police stations. We are able to geo-code all the 964 police stations for which the data on the number of FIRs registered is available. 


\title{
Figure 2: Effect of Air Pollution on Criminal Activity - OLS Estimation
}

\author{
(a) All Crimes
}

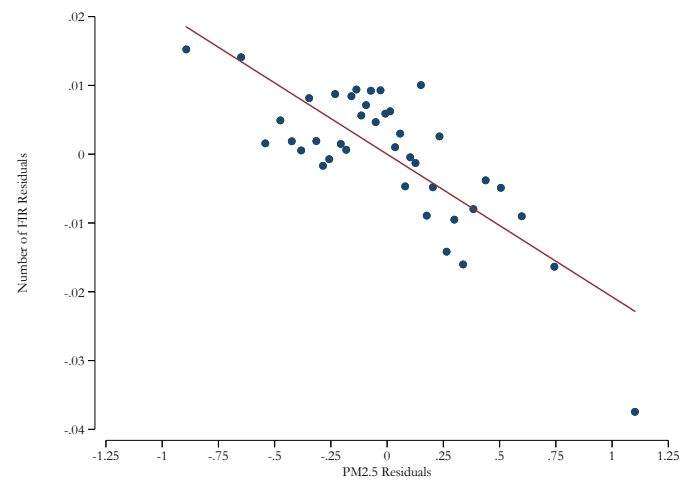

(b) Violent Crimes

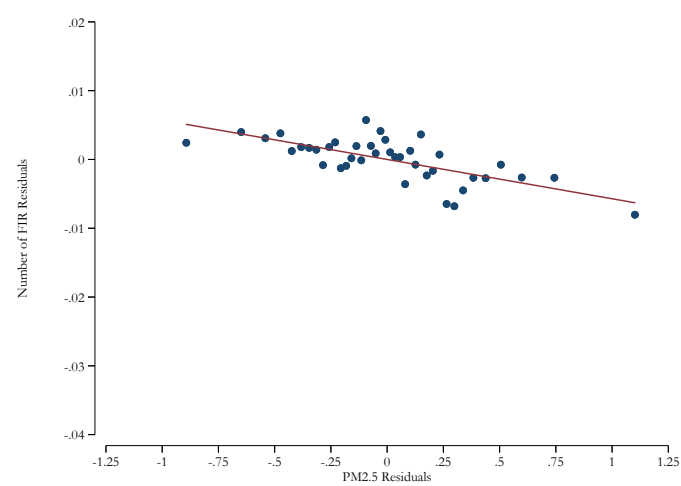

(c) Property Crimes

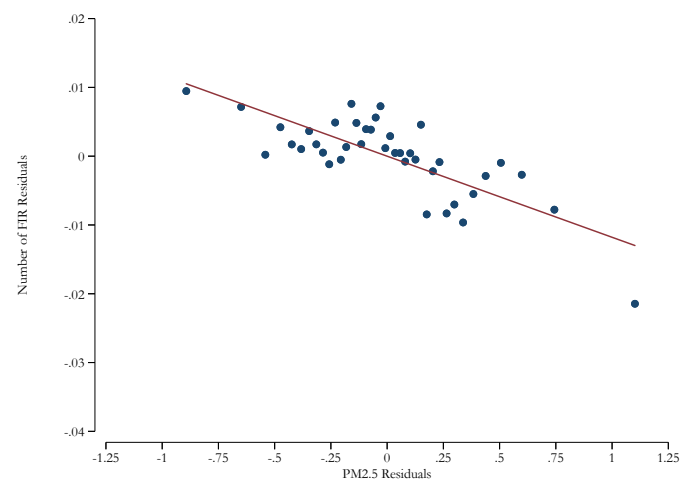

Note: Residual number of FIRs against residual PM2.5 concentration. Residuals are obtained from the regression of the number of FIRs and PM2.5 concentration on weather controls and the full set of fixed effects. Panel (2a) presents the results from the fixed effects OLS regression in equation (2). Panel (2b) presents results from the fixed effects OLS regression in equation (2) only for the FIRs that pertain to violent crimes. Panel (2c) presents results from the fixed effects OLS regression in equation (2) only for the FIRs that pertain to property crimes. Binned scatter is used to plot these residuals. The police station panel is used to obtain the estimates. The sample contains data from January 2015 to December 2019. 
Figure 3: Effect of Air Pollution on Criminal Activity - Instrumental Variable Estimation

(a) All Crimes

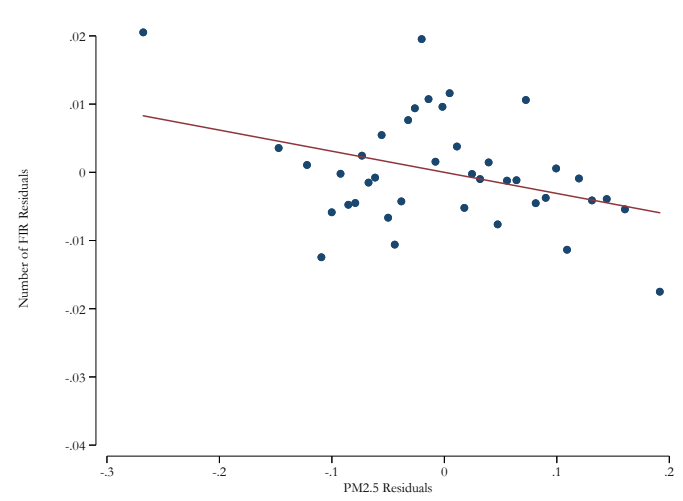

(b) Violent Crimes

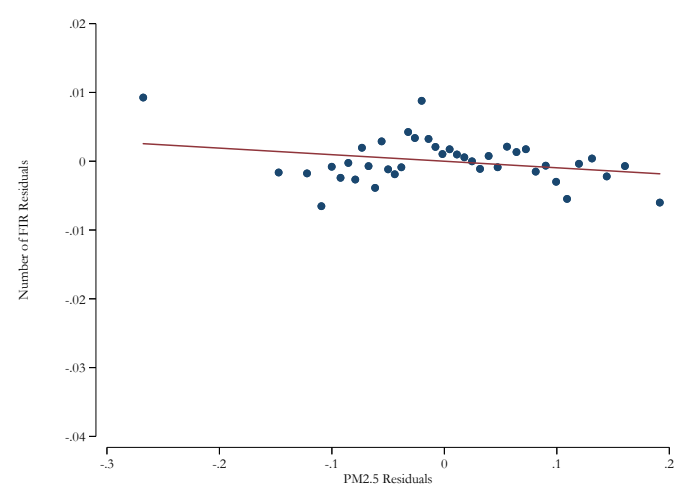

(c) Property Crimes

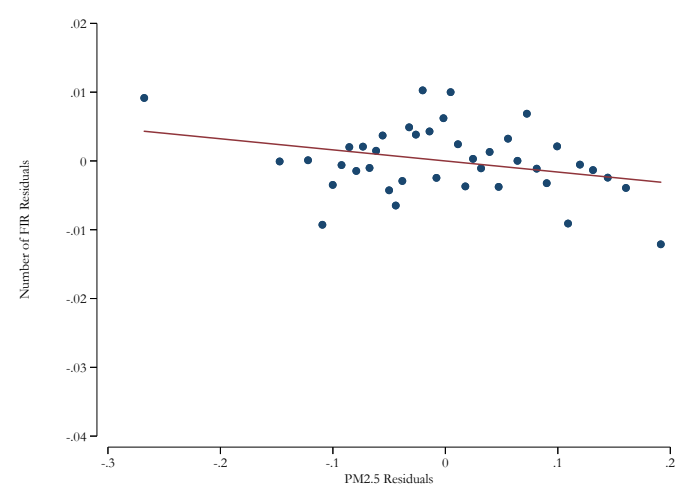

Note: Residual number of FIRs against residual PM2.5 concentration. Residuals are obtained from the regression of the number of FIRs and PM2.5 concentration on weather controls and the full set of fixed effects. Local variation in wind direction is used to instrument for PM2.5 concentration at the police station. Panel (3a) presents the results from the regression in equation (2) where PM2.5 concentration is instrumented in a way outlined in equation (4). Panel (3b) presents results from the regression in equation (2) where PM2.5 concentration is instrumented in a way outlined in equation (4) only for the FIRs that pertain to violent crimes. Panel (3c) presents results from the regression in equation (2) where PM2.5 concentration is instrumented in a way outlined in equation (4) only for the FIRs that pertain to property crimes. Binned scatter is used to plot these residuals. The police station panel is used to obtain the estimates. The sample contains data from January 2015 to December 2019. 
Figure 4: Effect of PM2.5 concentration on number of FIRs registered - Dropping Years and OLS Estimation

(a) All Crimes

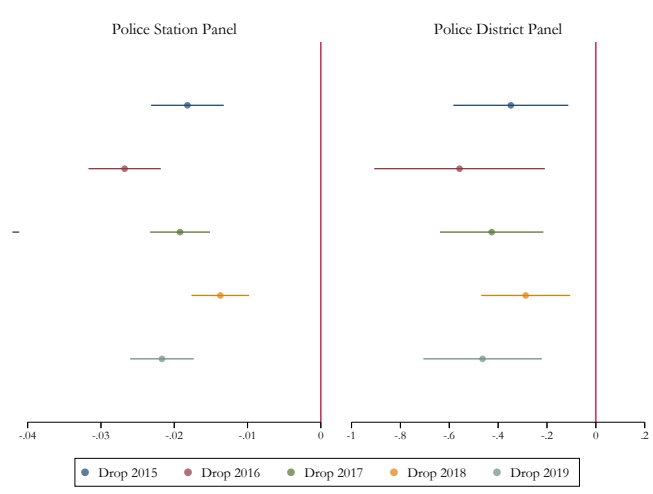

(b) Violent Crimes

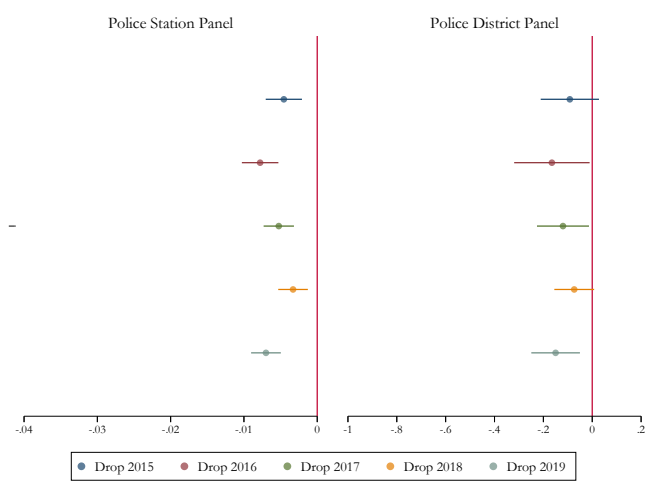

(c) Property Crimes

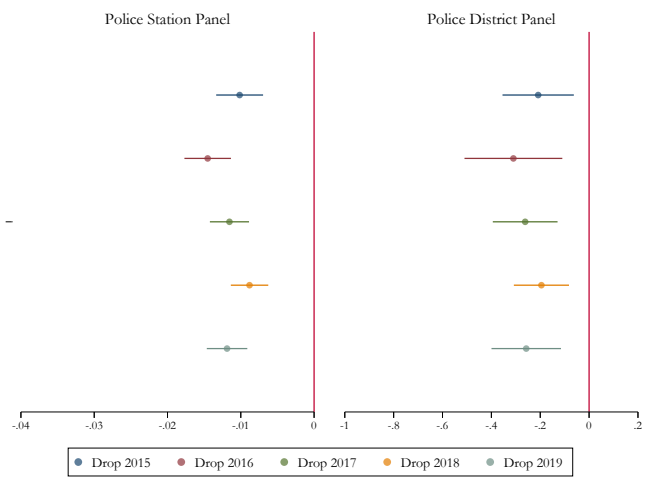

Note: Point estimates and the associated 95 percent confidence interval are presented. We obtain the point estimates by dropping one year from our sample at a time and estimating the specification in equation (2) for both the police station panel and police district panel. The sample contains data from January 2015 to December 2019. 
Figure 5: Effect of PM2.5 concentration on number of FIRs registered- Dropping Years and Instrumental Variable Estimation

(a) All Crimes

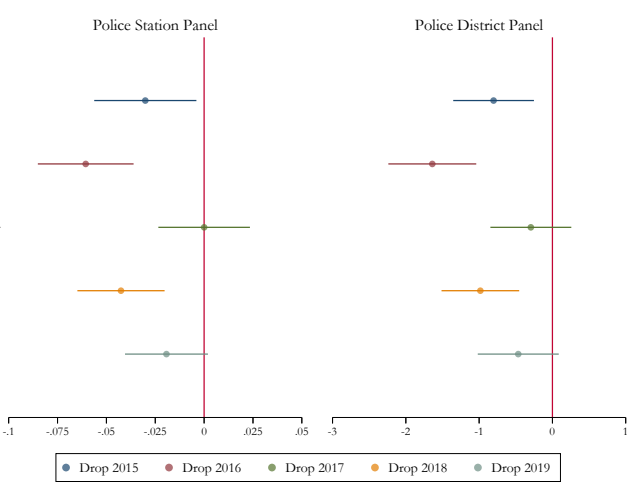

(b) Violent Crimes

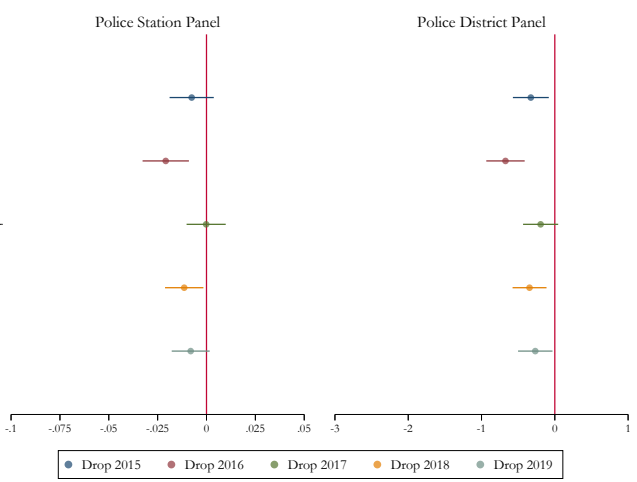

(c) Property Crimes

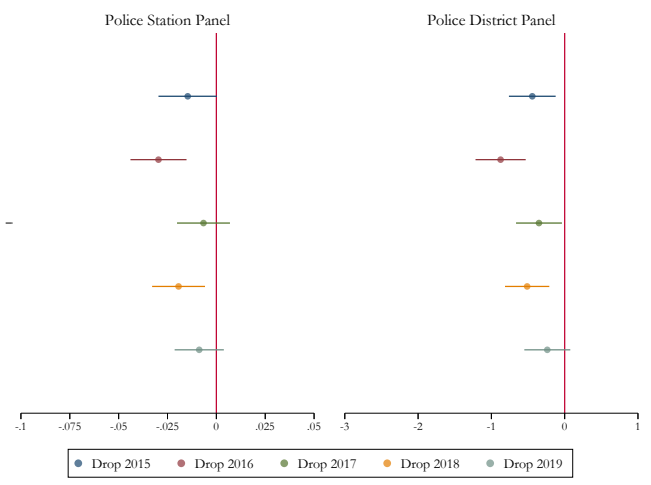

Note: Effect of PM2.5 concentration on the number of FIRs registered-Dropping Years. Point estimates and the associated 95 percent confidence interval are presented. We obtain the point estimates by dropping one year from our sample at a time and estimating the specification in equation (2) where we instrument for PM2.5 concentration using variation in local wind direction as outlined in equation (4) for both the police station panel and police district panel. The sample contains data from January 2015 to December 2019. 
Table 1: Summary Statistics - Analytical Sample

\begin{tabular}{|c|c|c|}
\hline & Mean & SD \\
\hline \multicolumn{3}{|c|}{ (A) First Information Report (FIR) Crimes } \\
\hline Number of FIR - All Crimes & 0.397 & 0.952 \\
\hline Number of FIR - Violent Crimes & 0.147 & 0.495 \\
\hline Number of FIR - Property Crimes & 0.198 & 0.621 \\
\hline \multicolumn{3}{|l|}{ (B) Pollution } \\
\hline$P M 2.5\left(\mu \mathrm{g} / \mathrm{m}^{3}\right)$ & 150.355 & 96.038 \\
\hline \multicolumn{3}{|l|}{ (C) Weather } \\
\hline Dewpoint Temperature (K) & 291.636 & 6.114 \\
\hline Surface Pressure (mmHg) & 99991.117 & 768.028 \\
\hline Temperature (K) & 298.570 & 5.216 \\
\hline Total Precipitation (m) & 0.002 & 0.004 \\
\hline Wind Speed $(\mathrm{m} / \mathrm{s})$ & 2.036 & 1.193 \\
\hline Observations & $1,760,264$ & \\
\hline
\end{tabular}

Notes: Each observation correspond to the unique date and is at the police station level. There are 964 police stations in the sample. Panel A presents summary statistics of data from the State Crime Records Bureau, Bihar. Panel B presents summary statistics of data from the EAC4 (ECMWF Atmospheric Composition Reanalysis 4). PM2.5 concentration is aggregated to 24 hour measure. Panel C presents summary statistics of data from the ERA5-Land. Weather variables aggregated to 24 hour measure. The sample contains data from January 2015 to December 2019. 
Table 2: Effect of PM2.5 concentration on number of FIR - Main Effect

\begin{tabular}{|c|c|c|c|c|c|c|c|c|c|c|c|c|}
\hline & $\begin{array}{c}(1) \\
\text { OLS } \\
\text { (All } \\
\text { Crimes) }\end{array}$ & $\begin{array}{c}\text { (2) } \\
\text { IV } \\
\text { (All } \\
\text { Crimes) }\end{array}$ & $\begin{array}{c}\text { (3) } \\
\text { OLS } \\
\text { (Violent } \\
\text { Crimes) }\end{array}$ & $\begin{array}{c}(4) \\
\text { IV } \\
\text { (Violent } \\
\text { Crimes) }\end{array}$ & $\begin{array}{c}(5) \\
\text { OLS } \\
\text { (Property } \\
\text { Crimes) }\end{array}$ & $\begin{array}{c}\text { (6) } \\
\text { IV } \\
\text { (Property } \\
\text { Crimes) }\end{array}$ & $\begin{array}{c}(7) \\
\text { OLS } \\
\text { (All } \\
\text { Crimes) }\end{array}$ & $\begin{array}{c}\text { (8) } \\
\text { IV } \\
\text { (All } \\
\text { Crimes) }\end{array}$ & $\begin{array}{c}\text { (9) } \\
\text { OLS } \\
\text { (Violent } \\
\text { Crimes) }\end{array}$ & $\begin{array}{c}\text { (10) } \\
\text { IV } \\
\text { (Violent } \\
\text { Crimes) }\end{array}$ & $\begin{array}{c}(11) \\
\text { OLS } \\
\text { (Property } \\
\text { Crimes) }\end{array}$ & $\begin{array}{c}(12) \\
\text { IV } \\
\text { (Property } \\
\text { Crimes) }\end{array}$ \\
\hline PM2.5 & $\begin{array}{c}-0.021 \\
(0.002)^{* * *} \\
{[0.002]^{* * *}}\end{array}$ & $\begin{array}{c}-0.031 \\
(0.011)^{* * *} \\
{[0.007]^{* * *}}\end{array}$ & $\begin{array}{c}-0.006 \\
(0.001)^{* * *} \\
{[0.001]^{* * *}}\end{array}$ & $\begin{array}{c}-0.010 \\
(0.005)^{* *} \\
{[0.004]^{* *}}\end{array}$ & $\begin{array}{c}-0.012 \\
(0.001)^{* * *} \\
{[0.001]^{* * *}}\end{array}$ & $\begin{array}{c}-0.016 \\
(0.006)^{* *} \\
{[0.005]^{* * *}}\end{array}$ & $\begin{array}{c}-0.434 \\
(0.110)^{* * *}\end{array}$ & $\begin{array}{c}-0.855 \\
(0.257)^{* * *}\end{array}$ & $\begin{array}{c}-0.122 \\
(0.052)^{* *}\end{array}$ & $\begin{array}{c}-0.364 \\
(0.111)^{* * *}\end{array}$ & $\begin{array}{c}-0.255 \\
(0.067)^{* * *}\end{array}$ & $\begin{array}{c}-0.496 \\
(0.146)^{* * *}\end{array}$ \\
\hline $\begin{array}{l}\text { Weather Controls } \\
\text { Police Station FE }\end{array}$ & $\begin{array}{l}\checkmark \\
\checkmark\end{array}$ & $\begin{array}{l}\checkmark \\
\checkmark\end{array}$ & $\begin{array}{l}\checkmark \\
\checkmark\end{array}$ & $\begin{array}{l}\checkmark \\
\checkmark\end{array}$ & $\begin{array}{l}\checkmark \\
\checkmark\end{array}$ & $\begin{array}{l}\checkmark \\
\checkmark\end{array}$ & $\checkmark$ & $\checkmark$ & $\checkmark$ & $\checkmark$ & $\checkmark$ & $\checkmark$ \\
\hline District FE & & & & & & & $\checkmark$ & $\checkmark$ & $\checkmark$ & $\checkmark$ & $\checkmark$ & $\checkmark$ \\
\hline Year FE & $\checkmark$ & $\checkmark$ & $\checkmark$ & $\checkmark$ & $\checkmark$ & $\checkmark$ & $\checkmark$ & $\checkmark$ & $\checkmark$ & $\checkmark$ & $\checkmark$ & $\checkmark$ \\
\hline Week FE & $\checkmark$ & $\checkmark$ & $\checkmark$ & $\checkmark$ & $\checkmark$ & $\checkmark$ & $\checkmark$ & $\checkmark$ & $\checkmark$ & $\checkmark$ & $\checkmark$ & $\checkmark$ \\
\hline Day of Week FE & $\checkmark$ & $\checkmark$ & $\checkmark$ & $\checkmark$ & $\checkmark$ & $\checkmark$ & $\checkmark$ & $\checkmark$ & $\checkmark$ & $\checkmark$ & $\checkmark$ & $\checkmark$ \\
\hline Month FE & $\checkmark$ & $\checkmark$ & $\checkmark$ & $\checkmark$ & $\checkmark$ & $\checkmark$ & $\checkmark$ & $\checkmark$ & $\checkmark$ & $\checkmark$ & $\checkmark$ & $\checkmark$ \\
\hline $\begin{array}{l}\text { Baseline Mean } \\
\text { F-Statistic: First Stage }\end{array}$ & 0.397 & $\begin{array}{c}0.397 \\
558.117\end{array}$ & 0.147 & $\begin{array}{c}0.147 \\
558.117\end{array}$ & 0.198 & $\begin{array}{c}0.198 \\
558.117\end{array}$ & 8.148 & $\begin{array}{c}8.148 \\
87.999\end{array}$ & 3.023 & $\begin{array}{c}3.023 \\
87.999\end{array}$ & 4.053 & $\begin{array}{c}4.053 \\
87.999\end{array}$ \\
\hline Police Stations & 964 & 964 & 964 & 964 & 964 & 964 & & & & & & \\
\hline $\begin{array}{l}\text { Districts } \\
\mathrm{N}\end{array}$ & $1,760,264$ & $1,760,264$ & $1,760,264$ & $1,760,264$ & $1,760,264$ & $1,760,264$ & $\begin{array}{c}47 \\
85,822\end{array}$ & $\begin{array}{c}47 \\
85,822\end{array}$ & $\begin{array}{c}47 \\
85,822\end{array}$ & $\begin{array}{c}47 \\
85,822\end{array}$ & $\begin{array}{c}47 \\
85,822\end{array}$ & $\begin{array}{c}47 \\
85,822\end{array}$ \\
\hline
\end{tabular}

Notes: Heteroskedasticity robust standard errors clustered by the police station in column (1) to column (6) and by the districts in column (7) to column (12) are in parentheses. Standard errors that correct for spatial and serial correlation in column (1) to column (6) are in square brackets (Barrios et al. (2012), Hsiang (2010), and Kelly (2019)). $\left({ }^{*} \mathrm{p}<.10{ }^{* *} \mathrm{p}<.05^{* * *} \mathrm{p}<.01\right)$. We are unable to correct for spatial and serial correlation in column (7) to column (12) because of the non-availability of the police district geoinformation. Each observation in column (1) to column (6) corresponds to the unique date and is at the police station level. Each observation in column (7) to column (12) corresponds to the unique date and is at the district level. The dependent variable in column (1) and column (2) is the total number of FIRs registered at the police station on a given day. The dependent variable in column (3) and column (4) is the total number of FIRs registered under the IPC sections that pertain to violent crimes at the police station on a given day. The dependent variable in column (5) and column (6) is the total number of FIRs registered under the IPC sections that pertain to property crimes at the police station on a given day. The dependent variable in column (7) and column (8) is the total number of FIRs registered in the district on a given day. The dependent variable in column (9) and column (10) is the total number of FIRs registered under the IPC sections that pertain to violent crimes in the district on a given day. The dependent variable in column (11) and column (12) is the total number of FIRs registered under the IPC sections that pertain to property crimes in the district on a given day. Each column regresses the dependent variable on the PM2.5 concentration measure, weather controls, and set of fixed effects. PM2.5 concentration measure has been standardized to have a standard deviation of 1 . Weather controls contain cumulative precipitation, temperature, dew point temperature, sea level pressure, and wind speed in flexible non-parametric form, with the indicator for the observation to be in one of the quartiles of the overall distribution over the sample period. The sample contains data from January 2015 to December 2019. Districts in column (7) to column (12) refer to the police districts. 
Table 3: Effect of PM2.5 concentration on number of FIR - PPML

\begin{tabular}{lcccccc}
\hline & $(1)$ & $(2)$ & $(3)$ & $(4)$ & $(5)$ & $(6)$ \\
& $\begin{array}{l}\text { (All } \\
\text { Crimes) }\end{array}$ & $\begin{array}{c}\text { (Violent } \\
\text { Crimes) }\end{array}$ & $\begin{array}{c}\text { (Property } \\
\text { Crimes) }\end{array}$ & $\begin{array}{c}\text { (All } \\
\text { Crimes) }\end{array}$ & $\begin{array}{c}\text { (Violent } \\
\text { Crimes) }\end{array}$ & $\begin{array}{c}\text { (Property } \\
\text { Crimes) }\end{array}$ \\
\hline PM2.5 & -0.064 & -0.055 & -0.068 & -0.059 & -0.053 & -0.064 \\
& $(0.005)^{* * *}$ & $(0.007)^{* * *}$ & $(0.007)^{* * *}$ & $(0.010)^{* * *}$ & $(0.013)^{* * *}$ & $(0.012)^{* * *}$ \\
Weather Controls & $\checkmark$ & $\checkmark$ & $\checkmark$ & $\checkmark$ & $\checkmark$ & $\checkmark$ \\
Police Station FE & $\checkmark$ & $\checkmark$ & $\checkmark$ & & & \\
District FE & & & & $\checkmark$ & $\checkmark$ & $\checkmark$ \\
Year FE & $\checkmark$ & $\checkmark$ & $\checkmark$ & $\checkmark$ & $\checkmark$ & $\checkmark$ \\
Week FE & $\checkmark$ & $\checkmark$ & $\checkmark$ & $\checkmark$ & $\checkmark$ & $\checkmark$ \\
Day of Week FE & $\checkmark$ & $\checkmark$ & $\checkmark$ & $\checkmark$ & $\checkmark$ & $\checkmark$ \\
Month FE & $\checkmark$ & $\checkmark$ & $\checkmark$ & $\checkmark$ & $\checkmark$ & $\checkmark$ \\
Baseline Mean & 0.397 & 0.147 & 0.198 & 8.148 & 3.023 & 4.053 \\
Police Stations & 964 & 964 & 964 & & & \\
Districts & & & & 47 & 47 & 47 \\
N & $1,760,264$ & $1,760,264$ & $1,760,264$ & 85,822 & 85,822 & 85,822 \\
\hline
\end{tabular}

Notes: Heteroskedasticity robust standard errors clustered by the police station in column (1), column (2), and column (3) and by the districts in column (4), column (5), and column (6) are in parentheses. (* $\mathrm{p}<.10^{* *} \mathrm{p}<.05^{* * *} \mathrm{p}<.01$ ). Each observation in column (1), column (2), and column (3) corresponds to the unique date and is at the police station level. Each observation in column (4), column (5), and column (6) corresponds to the unique date and is at the district level. The dependent variable in column (1) and column (4) is the total number of FIRs registered at the police station on a given day and in the district on a given day, respectively. The dependent variable in column (2) and column (5) is the total number of FIRs registered under the IPC sections that pertain to violent crimes at the police station on a given day and in the district on a given day, respectively. The dependent variable in column (3) and column (6) is the total number of FIRs registered under the IPC sections that pertain to property crimes at the police station on a given day and in the district on a given day, respectively. Each column regresses the dependent variable on the PM2.5 concentration measure, weather controls, and set of fixed effects. PM2.5 concentration measure has been standardized to have a standard deviation of 1 . Weather controls contain cumulative precipitation, temperature, dew point temperature, sea level pressure, and wind speed in flexible non-parametric form, with the indicator for the observation to be in one of the quartiles of the overall distribution over the sample period. The sample contains data from January 2015 to December 2019. Districts in column (4), column (5), and column (6) refer to police districts. 
Table 4: Effect of PM2.5 concentration on number of complaints - NCW Data

\begin{tabular}{lcccc}
\hline & $(1)$ & $(2)$ & $(3)$ & $(4)$ \\
& (OLS) & (PPML) & (OLS) & (PPML) \\
\hline PM2.5 & -0.097 & -0.003 & -1.703 & -0.035 \\
& $(0.164)$ & $(0.097)$ & $(2.084)$ & $(0.037)$ \\
Weather Controls & $\checkmark$ & $\checkmark$ & $\checkmark$ & $\checkmark$ \\
District FE & $\checkmark$ & $\checkmark$ & & \\
Year FE & $\checkmark$ & $\checkmark$ & $\checkmark$ & $\checkmark$ \\
Month FE & $\checkmark$ & $\checkmark$ & $\checkmark$ & $\checkmark$ \\
Week FE & & & $\checkmark$ & $\checkmark$ \\
Day of Week FE & & & $\checkmark$ & $\checkmark$ \\
& & & & \\
Data & Monthly & Monthly & Daily & Daily \\
Baseline Mean & 1.439 & 1.439 & 52.950 & 52.950 \\
Districts & 38 & 38 & & \\
N & 2,320 & 2,320 & 1,826 & 1,826 \\
\hline
\end{tabular}

Notes: Heteroskedasticity robust standard errors clustered by the district in column (1) and column (2) are in parentheses. Heteroskedasticity robust standard errors in column (3) and column (4) are in parentheses. ( ${ }^{*} \mathrm{p}<.10^{* *} \mathrm{p}<.05^{* * *} \mathrm{p}<.01$ ). Each observation in column (1) and column (2) corresponds to a unique month and is at the district level. Each observation in column (3) and column (4) corresponds to a unique date and is at the India level. The dependent variable in column (1) and column (2) is the number of complaints received by NCW in a given month. The dependent variable in column (3) and column (4) is the number of complaints received by NCW on a given day. Each column regresses the dependent variable on the PM2.5 concentration measure, weather controls, and set of fixed effects. PM2.5 concentration measure has been standardized to have a standard deviation of 1 . Weather controls contain cumulative precipitation, temperature, dew point temperature, sea level pressure, and wind speed in flexible non-parametric form, with the indicator for the observation to be in one of the quartiles of the overall distribution over the sample period. The sample contains data from January 2015 to December 2019. Districts in column (1) and column (2) refer to the administrative districts in the state of Bihar. 
Table 5: Effect of PM2.5 concentration on domestic violence and local crime - DHS and IHDS data

\begin{tabular}{|c|c|c|c|c|c|c|c|c|c|c|}
\hline & $\begin{array}{c}(1) \\
\text { (OLS) } \\
\text { (Any Domestic } \\
\text { Violence) }\end{array}$ & $\begin{array}{c}(2) \\
\text { (OLS) } \\
\text { (Physical } \\
\text { Violence) }\end{array}$ & $\begin{array}{c}(3) \\
(\text { OLS) } \\
\text { (Emotional } \\
\text { Violence) }\end{array}$ & $\begin{array}{c}(4) \\
\text { (OLS) } \\
\text { (Local Crime: } \\
\text { All) }\end{array}$ & $\begin{array}{c}(5) \\
\text { (OLS) } \\
\text { (Local Crime: } \\
\text { Violent) }\end{array}$ & $\begin{array}{c}(6) \\
\text { (OLS) } \\
\text { (Local Crime: } \\
\text { Property) }\end{array}$ & $\begin{array}{c}(7) \\
\text { (OLS) } \\
\text { LC1 }\end{array}$ & $\begin{array}{c}(8) \\
\text { (OLS) } \\
\text { LC2 }\end{array}$ & $\begin{array}{c}(9) \\
\text { (OLS) } \\
\text { LC3 }\end{array}$ & $\begin{array}{c}(10) \\
(\mathrm{OLS}) \\
\mathrm{LC} 4\end{array}$ \\
\hline PM2.5 & $\begin{array}{c}0.007 \\
(0.039)\end{array}$ & $\begin{array}{c}0.004 \\
(0.037)\end{array}$ & $\begin{array}{c}0.026 \\
(0.033)\end{array}$ & $\begin{array}{c}-0.076 \\
(0.262)\end{array}$ & $\begin{array}{c}-0.196 \\
(0.094)^{*}\end{array}$ & $\begin{array}{c}-0.338 \\
(0.308)\end{array}$ & $\begin{array}{l}-0.199 \\
(0.286)\end{array}$ & $\begin{array}{c}-0.290 \\
(0.127)^{* *}\end{array}$ & $\begin{array}{c}0.231 \\
(0.260)\end{array}$ & $\begin{array}{l}-0.468 \\
(0.571)\end{array}$ \\
\hline Household Controls & $\checkmark$ & $\checkmark$ & $\checkmark$ & $\checkmark$ & $\checkmark$ & $\checkmark$ & $\checkmark$ & $\checkmark$ & $\checkmark$ & $\checkmark$ \\
\hline Weather Controls & $\checkmark$ & $\checkmark$ & $\checkmark$ & $\checkmark$ & $\checkmark$ & $\checkmark$ & $\checkmark$ & $\checkmark$ & $\checkmark$ & $\checkmark$ \\
\hline District FE & $\checkmark$ & $\checkmark$ & $\checkmark$ & $\checkmark$ & $\checkmark$ & $\checkmark$ & $\checkmark$ & $\checkmark$ & $\checkmark$ & $\checkmark$ \\
\hline Year FE & $\checkmark$ & $\checkmark$ & $\checkmark$ & $\checkmark$ & $\checkmark$ & $\checkmark$ & $\checkmark$ & $\checkmark$ & $\checkmark$ & $\checkmark$ \\
\hline Data & DHS & DHS & DHS & IHDS & IHDS & IHDS & IHDS & IHDS & IHDS & IHDS \\
\hline Districts & 38 & 38 & 38 & 17 & 17 & 17 & 17 & 17 & 17 & 17 \\
\hline $\mathrm{N}$ & 4,728 & 4,728 & 4,728 & 1,546 & 1,546 & 1,546 & 1,546 & 1,546 & 1,546 & 1,546 \\
\hline
\end{tabular}

Notes: Heteroskedasticity robust standard errors clustered by the district are in parentheses $\left({ }^{*} \mathrm{p}<.10 * *\right.$ $\left.\mathrm{p}<.05^{* * *} \mathrm{p}<.01\right)$. Each observation in all the columns corresponds to a unique respondent. The variable of interest in each column is the mean PM2.5 concentration in the last twelve months relative to the date of the interview. PM2.5 concentration measure has been standardized to have a standard deviation of 1 . The dependent variable in column (1) is an indicator variable for whether the respondent reported any act of domestic violence in the last twelve months. This variable is constructed using the information on whether the respondent reported any act of physical, sexual, or emotional violence in the last twelve months. The dependent variable in column (2) is an indicator variable for whether the respondent reported any act of physical or sexual violence by the husband, partner, or other household members in the last twelve months. The dependent variable in column (3) is an indicator variable for whether the respondent reported any act of emotional violence by the husband, partner, or other household members in the last twelve months. The dependent variable in column (4) is an indicator variable for whether the respondent reported any act of local crime in the last twelve months. This variable is constructed using the information on whether anyone attacked any household member in the house, the incidence of harassment of unmarried girls in the village or the neighborhood, whether anything was stolen, whether anyone tried to illegally enter the house. Column (5) and column (6) generate indicator variables for the reporting of violent crimes and property crimes by the respondent by using the information from the first two and last two of these, respectively. The dependent variable in column (7) is whether the respondent reported anything was stolen from the household in the last twelve months. The dependent variable in column (8) is whether the respondent reported anyone breaking or getting in the house illegally in the last twelve months. The dependent variable in column (9) is whether the respondent reported anyone in the household was threatened or attacked in the last twelve months. The dependent variable in column (10) is whether the respondent reported frequent harassment of unmarried girls in the neighborhood. Household controls in column (1), column(2), and column(3) are the highest education level in the household, religion, number of members in the household, and the wealth index. Household controls in column (4), column (5), column (6), column (7), column (8), column (9), column (10) are the highest education level in the household, religion, number of members in the household, and the income of the household. In all columns, weather controls contain cumulative precipitation, temperature, dew point temperature, sea level pressure, and wind speed. All of these are mean in the last twelve months relative to the date of the interview. 
Table 6: Effect of PM2.5 concentration on number of FIR - Alternate Fixed Effects

\begin{tabular}{|c|c|c|c|c|c|c|c|c|c|c|}
\hline & $\begin{array}{l}(1) \\
(\mathrm{OLS})\end{array}$ & $\begin{array}{l}(2) \\
\text { (IV) }\end{array}$ & $\begin{array}{l}(3) \\
\text { (OLS) }\end{array}$ & $\begin{array}{l}(4) \\
\text { (IV) }\end{array}$ & $\begin{array}{l}(5) \\
(\mathrm{OLS})\end{array}$ & $\begin{array}{l}\text { (6) } \\
\text { (IV) }\end{array}$ & $\begin{array}{l}(7) \\
(\mathrm{OLS})\end{array}$ & $\begin{array}{l}\text { (8) } \\
\text { (IV) }\end{array}$ & $\begin{array}{l}(9) \\
\text { (OLS) }\end{array}$ & $\begin{array}{l}\text { (10) } \\
\text { (IV) }\end{array}$ \\
\hline \multicolumn{11}{|l|}{ (A) All Crimes } \\
\hline PM2.5 & $\begin{array}{c}-0.021 \\
(0.002)^{* * *} \\
{[0.002]^{* * *}}\end{array}$ & $\begin{array}{c}-0.031 \\
(0.011)^{* * *} \\
{[0.007]^{* * *}}\end{array}$ & $\begin{array}{c}-0.020 \\
(0.002)^{* * *} \\
{[0.002]^{* * *}}\end{array}$ & $\begin{array}{c}-0.027 \\
(0.011)^{* *} \\
{[0.007]^{* * *}}\end{array}$ & $\begin{array}{c}-0.005 \\
(0.002)^{* * *} \\
{[0.002]^{* * *}}\end{array}$ & $\begin{array}{c}-0.047 \\
(0.011)^{* * *} \\
{[0.012]^{* * *}}\end{array}$ & $\begin{array}{c}-0.006 \\
(0.002)^{* * *} \\
{[0.002]^{* * *}}\end{array}$ & $\begin{array}{c}-0.030 \\
(0.012)^{* *} \\
{[0.007]^{* * *}}\end{array}$ & $\begin{array}{l}-0.003 \\
(0.002) \\
{[0.002]}\end{array}$ & $\begin{array}{c}-0.015 \\
(0.013) \\
{[0.008]^{* *}}\end{array}$ \\
\hline Baseline Mean & 0.397 & 0.397 & 0.397 & 0.397 & 0.397 & 0.397 & 0.397 & 0.397 & 0.397 & 0.397 \\
\hline \multicolumn{11}{|l|}{ (B) Violent Crimes } \\
\hline PM2.5 & $\begin{array}{c}-0.006 \\
(0.001)^{* * *} \\
{[0.001]^{* * *}}\end{array}$ & $\begin{array}{c}-0.010 \\
(0.005)^{* *} \\
{[0.004]^{* *}}\end{array}$ & $\begin{array}{c}-0.006 \\
(0.001)^{* * *} \\
{[0.001]^{* * *}}\end{array}$ & $\begin{array}{c}-0.008 \\
(0.005)^{*} \\
{[0.004]^{* *}}\end{array}$ & $\begin{array}{l}-0.000 \\
(0.001) \\
{[0.001]}\end{array}$ & $\begin{array}{l}-0.010 \\
(0.007) \\
{[0.007]}\end{array}$ & $\begin{array}{l}-0.001 \\
(0.001) \\
{[0.001]}\end{array}$ & $\begin{array}{c}-0.009 \\
(0.005)^{*} \\
{[0.004]^{* *}}\end{array}$ & $\begin{array}{l}-0.001 \\
(0.001) \\
{[0.001]}\end{array}$ & $\begin{array}{l}-0.006 \\
(0.006) \\
{[0.004]}\end{array}$ \\
\hline Baseline Mean & 0.147 & 0.147 & 0.147 & 0.147 & 0.147 & 0.147 & 0.147 & 0.147 & 0.147 & 0.147 \\
\hline \multicolumn{11}{|l|}{ (C) Property Crimes } \\
\hline PM2.5 & $\begin{array}{c}-0.012 \\
(0.001)^{* * *} \\
{[0.001]^{* * *}}\end{array}$ & $\begin{array}{c}-0.016 \\
(0.006)^{* *} \\
{[0.005]^{* * *}}\end{array}$ & $\begin{array}{c}-0.012 \\
(0.001)^{* * *} \\
{[0.001]^{* * *}}\end{array}$ & $\begin{array}{c}-0.013 \\
(0.006)^{* *} \\
{[0.005]^{* * *}}\end{array}$ & $\begin{array}{c}-0.003 \\
(0.001)^{* *} \\
{[0.001]^{* *}}\end{array}$ & $\begin{array}{c}-0.028 \\
(0.008)^{* * *} \\
{[0.008]^{* * *}}\end{array}$ & $\begin{array}{c}-0.004 \\
(0.001)^{* * *} \\
{[0.001]^{* * *}}\end{array}$ & $\begin{array}{c}-0.016 \\
(0.007)^{* *} \\
{[0.005]^{* * *}}\end{array}$ & $\begin{array}{c}-0.003 \\
(0.001)^{* *} \\
{[0.001]^{* * *}}\end{array}$ & $\begin{array}{l}-0.007 \\
(0.007) \\
{[0.005]}\end{array}$ \\
\hline Weather Controls & $\checkmark$ & $\checkmark$ & $\checkmark$ & $\checkmark$ & $\checkmark$ & $\checkmark$ & $\checkmark$ & $\checkmark$ & $\checkmark$ & $\checkmark$ \\
\hline Police Station FE & $\checkmark$ & $\checkmark$ & $\checkmark$ & $\checkmark$ & $\checkmark$ & $\checkmark$ & $\checkmark$ & $\checkmark$ & $\checkmark$ & $\checkmark$ \\
\hline Year FE & $\checkmark$ & $\checkmark$ & $\checkmark$ & $\checkmark$ & $\checkmark$ & $\checkmark$ & $\checkmark$ & $\checkmark$ & $\checkmark$ & $\checkmark$ \\
\hline Month FE & $\checkmark$ & $\checkmark$ & $\checkmark$ & $\checkmark$ & $\checkmark$ & $\checkmark$ & $\checkmark$ & $\checkmark$ & $\checkmark$ & $\checkmark$ \\
\hline Week FE & $\checkmark$ & $\checkmark$ & $\checkmark$ & $\checkmark$ & $\checkmark$ & $\checkmark$ & $\checkmark$ & $\checkmark$ & $\checkmark$ & $\checkmark$ \\
\hline Day of Week FE & $\checkmark$ & $\checkmark$ & $\checkmark$ & $\checkmark$ & $\checkmark$ & $\checkmark$ & $\checkmark$ & $\checkmark$ & $\checkmark$ & $\checkmark$ \\
\hline Distict x Year FE & & & $\checkmark$ & $\checkmark$ & & & & & & \\
\hline $\begin{array}{l}\text { District } \times \text { Month } x \text { Year FE } \\
\text { Month } \times \text { Year FE }\end{array}$ & & & & & $\checkmark$ & $\checkmark$ & $\checkmark$ & $\checkmark$ & & \\
\hline Week x Year FE & & & & & & & & & $\checkmark$ & $\checkmark$ \\
\hline $\begin{array}{l}\text { Baseline Mean } \\
\text { F-Statistic: First Stage }\end{array}$ & 0.198 & $\begin{array}{c}0.198 \\
558.117\end{array}$ & 0.198 & $\begin{array}{c}0.198 \\
564.747\end{array}$ & 0.198 & $\begin{array}{c}0.198 \\
385.838\end{array}$ & 0.198 & $\begin{array}{c}0.198 \\
497.493\end{array}$ & 0.198 & $\begin{array}{c}0.198 \\
359.297\end{array}$ \\
\hline Police Stations & 964 & 964 & 964 & 964 & 964 & 964 & 964 & 964 & 964 & 964 \\
\hline $\mathrm{N}$ & $1,760,264$ & $1,760,264$ & $1,760,264$ & $1,760,264$ & $1,760,264$ & $1,760,264$ & $1,760,264$ & $1,760,264$ & $1,760,264$ & $1,760,264$ \\
\hline
\end{tabular}

Notes: Heteroskedasticity robust standard errors clustered by the police station are in parentheses. Standard errors that correct for spatial and serial correlation are in square brackets (Barrios et al. (2012), Hsiang (2010), and Kelly (2019)). $\left({ }^{*} \mathrm{p}<.10^{* *} \mathrm{p}<.05^{* * *} \mathrm{p}<.01\right)$. Each observation in all columns corresponds to the unique date and is at the police station level. The dependent variable in Panel (A) is the total number of FIRs registered at the police station on a given day. The dependent variable in Panel (B) is the total number of FIRs registered under the IPC sections that pertain to violent crimes at the police station on a given day. The dependent variable in Panel (C) is the total number of FIRs registered under the IPC sections that pertain to property crimes at the police station on a given day. Each column regresses the dependent variable on the PM2.5 concentration measure, weather controls, and set of fixed effects. PM2.5 concentration measure has been standardized to have a standard deviation of 1 . Weather controls contain cumulative precipitation, temperature, dew point temperature, sea level pressure, and wind speed in flexible non-parametric form, with the indicator for the observation to be in one of the quartiles of the overall distribution over the sample period. The sample contains data from January 2015 to December 2019. 
Table 7: Effect of PM2.5 concentration on number of FIR - Alternate Fixed Effects

\begin{tabular}{|c|c|c|c|c|c|c|c|c|c|c|}
\hline & $\begin{array}{l}(1) \\
\text { (OLS) }\end{array}$ & $\begin{array}{l}(2) \\
\text { (IV) }\end{array}$ & $\begin{array}{c}(3) \\
\text { (OLS) }\end{array}$ & $\begin{array}{l}(4) \\
\text { (IV) }\end{array}$ & $\begin{array}{c}(5) \\
\text { (OLS) }\end{array}$ & $\begin{array}{l}(6) \\
\text { (IV) }\end{array}$ & $\begin{array}{c}(7) \\
\text { (OLS) }\end{array}$ & $\begin{array}{l}\text { (8) } \\
\text { (IV) }\end{array}$ & $\begin{array}{c}(9) \\
\text { (OLS) }\end{array}$ & $\begin{array}{l}\text { (10) } \\
\text { (IV) }\end{array}$ \\
\hline \multicolumn{11}{|l|}{ (A) All Crimes } \\
\hline PM2.5 & $\begin{array}{c}-0.434 \\
(0.110)^{* * *}\end{array}$ & $\begin{array}{c}-0.855 \\
(0.257)^{* * *}\end{array}$ & $\begin{array}{c}-0.403 \\
(0.094)^{* * *}\end{array}$ & $\begin{array}{c}-0.654 \\
(0.212)^{* * *}\end{array}$ & $\begin{array}{l}-0.092 \\
(0.050)^{*}\end{array}$ & $\begin{array}{c}-1.037 \\
(0.292)^{* * *}\end{array}$ & $\begin{array}{l}-0.140 \\
(0.085)\end{array}$ & $\begin{array}{c}-0.898 \\
(0.261)^{* * *}\end{array}$ & $\begin{array}{l}-0.067 \\
(0.104)\end{array}$ & $\begin{array}{c}-0.572 \\
(0.261)^{* *}\end{array}$ \\
\hline Baseline Mean & 8.148 & 8.148 & 8.148 & 8.148 & 8.148 & 8.148 & 8.148 & 8.148 & 8.148 & 8.148 \\
\hline \multicolumn{11}{|l|}{ (B) Violent Crimes } \\
\hline PM2.5 & $\begin{array}{c}-0.122 \\
(0.052)^{* *}\end{array}$ & $\begin{array}{c}-0.364 \\
(0.111)^{* * * *}\end{array}$ & $\begin{array}{c}-0.118 \\
(0.048)^{* *}\end{array}$ & $\begin{array}{c}-0.290 \\
(0.098)^{* * * *}\end{array}$ & $\begin{array}{l}-0.003 \\
(0.025)\end{array}$ & $\begin{array}{c}-0.311 \\
(0.153)^{* *}\end{array}$ & $\begin{array}{l}-0.030 \\
(0.046)\end{array}$ & $\begin{array}{c}-0.397 \\
(0.116)^{* * * *}\end{array}$ & $\begin{array}{l}-0.036 \\
(0.054)\end{array}$ & $\begin{array}{c}-0.327 \\
(0.119)^{* * * *}\end{array}$ \\
\hline Baseline Mean & 3.023 & 3.023 & 3.023 & 3.023 & 3.023 & 3.023 & 3.023 & 3.023 & 3.023 & 3.023 \\
\hline \multicolumn{11}{|l|}{ (C) Property Crimes } \\
\hline PM2.5 & $\begin{array}{c}-0.255 \\
(0.067)^{* * *}\end{array}$ & $\begin{array}{c}-0.496 \\
(0.146)^{* * *}\end{array}$ & $\begin{array}{c}-0.241 \\
(0.061)^{* * *}\end{array}$ & $\begin{array}{c}-0.370 \\
(0.125)^{* * *}\end{array}$ & $\begin{array}{c}-0.062 \\
(0.030)^{* *}\end{array}$ & $\begin{array}{c}-0.682 \\
(0.186)^{* * *}\end{array}$ & $\begin{array}{l}-0.099 \\
(0.051)^{*}\end{array}$ & $\begin{array}{c}-0.521 \\
(0.151)^{* * *}\end{array}$ & $\begin{array}{l}-0.076 \\
(0.062)\end{array}$ & $\begin{array}{c}-0.319 \\
(0.153)^{* *}\end{array}$ \\
\hline Weather Controls & $\checkmark$ & $\checkmark$ & $\checkmark$ & $\checkmark$ & $\checkmark$ & $\checkmark$ & $\checkmark$ & $\checkmark$ & $\checkmark$ & $\checkmark$ \\
\hline District FE & $\checkmark$ & $\checkmark$ & $\checkmark$ & $\checkmark$ & $\checkmark$ & $\checkmark$ & $\checkmark$ & $\checkmark$ & $\checkmark$ & $\checkmark$ \\
\hline Year FE & $\checkmark$ & $\checkmark$ & $\checkmark$ & $\checkmark$ & $\checkmark$ & $\checkmark$ & $\checkmark$ & $\checkmark$ & $\checkmark$ & $\checkmark$ \\
\hline Month FE & $\checkmark$ & $\checkmark$ & $\checkmark$ & $\checkmark$ & $\checkmark$ & $\checkmark$ & $\checkmark$ & $\checkmark$ & $\checkmark$ & $\checkmark$ \\
\hline Week FE & $\checkmark$ & $\checkmark$ & $\checkmark$ & $\checkmark$ & $\checkmark$ & $\checkmark$ & $\checkmark$ & $\checkmark$ & $\checkmark$ & $\checkmark$ \\
\hline Day of Week FE & $\checkmark$ & $\checkmark$ & $\checkmark$ & $\checkmark$ & $\checkmark$ & $\checkmark$ & $\checkmark$ & $\checkmark$ & $\checkmark$ & $\checkmark$ \\
\hline Distict $x$ Year FE & & & $\checkmark$ & $\checkmark$ & & & & & & \\
\hline District $\mathrm{x}$ Month $\mathrm{x}$ Year FE & & & & & $\checkmark$ & $\checkmark$ & & & & \\
\hline Month x Year FE & & & & & & & $\checkmark$ & $\checkmark$ & & \\
\hline Week x Year FE & & & & & & & & & $\checkmark$ & $\checkmark$ \\
\hline Baseline Mean & 4.053 & 4.053 & 4.053 & 4.053 & 4.053 & 4.053 & 4.053 & 4.053 & 4.053 & 4.053 \\
\hline F-Statistic: First Stage & & 87.999 & & 88.301 & & 33.960 & & 83.229 & & 84.178 \\
\hline Districts & 47 & 47 & 47 & 47 & 47 & 47 & 47 & 47 & 47 & 47 \\
\hline $\mathrm{N}$ & 85,822 & 85,822 & 85,822 & 85,822 & 85,822 & 85,822 & 85,822 & 85,822 & 85,822 & 85,822 \\
\hline
\end{tabular}

Notes: Heteroskedasticity robust standard errors clustered by the districts are in parentheses. $\left({ }^{*} \mathrm{p}<.10 * *\right.$ $\left.\mathrm{p}<.05^{* * *} \mathrm{p}<.01\right)$. Each observation in all columns corresponds to the unique date and is at the district level. The dependent variable in Panel (A) is the total number of FIRs registered in the district on a given day. The dependent variable in Panel (B) is the total number of FIRs registered under the IPC sections that pertain to violent crimes in the district on a given day. The dependent variable in Panel (C) is the total number of FIRs registered under the IPC sections that pertain to property crimes in the district on a given day. Each column regresses the dependent variable on the PM2.5 concentration measure, weather controls, and set of fixed effects. PM2.5 concentration measure has been standardized to have a standard deviation of 1 . Weather controls contain cumulative precipitation, temperature, dew point temperature, sea level pressure, and wind speed in flexible non-parametric form, with the indicator for the observation to be in one of the quartiles of the overall distribution over the sample period. The sample contains data from January 2015 to December 2019. Districts in all columns refer to police districts. 
Table 8: Effect of PM2.5 concentration on number of FIR - Alternate Radius

\begin{tabular}{|c|c|c|c|c|c|c|}
\hline & $\begin{array}{c}(1) \\
\text { (OLS) }\end{array}$ & $\begin{array}{l}(2) \\
\text { (IV) }\end{array}$ & $\begin{array}{c}(3) \\
\text { (OLS) }\end{array}$ & $\begin{array}{l}(4) \\
\text { (IV) }\end{array}$ & $\begin{array}{c}(5) \\
\text { (OLS) }\end{array}$ & $\begin{array}{l}\text { (6) } \\
\text { (IV) }\end{array}$ \\
\hline \multicolumn{7}{|l|}{ (A) All Crimes } \\
\hline PM2.5 & $\begin{array}{c}-0.021 \\
(0.002)^{* * *} \\
{[0.002]^{* * *}}\end{array}$ & $\begin{array}{c}-0.031 \\
(0.011)^{* * *} \\
{[0.007]^{* * *}}\end{array}$ & $\begin{array}{c}-0.020 \\
(0.002)^{* * *} \\
{[0.002]^{* * *}}\end{array}$ & $\begin{array}{c}-0.030 \\
(0.011)^{* * *} \\
{[0.007]^{* * *}}\end{array}$ & $\begin{array}{c}-0.022 \\
(0.002)^{* * *} \\
{[0.002]^{* * *}}\end{array}$ & $\begin{array}{c}-0.032 \\
(0.011)^{* * *} \\
{[0.007]^{* * *}}\end{array}$ \\
\hline Baseline Mean & 0.397 & 0.397 & 0.397 & 0.397 & 0.397 & 0.397 \\
\hline \multicolumn{7}{|l|}{ (B) Violent Crimes } \\
\hline PM2.5 & $\begin{array}{c}-0.006 \\
(0.001)^{* * *} \\
{[0.001]^{* * *}}\end{array}$ & $\begin{array}{c}-0.010 \\
(0.005)^{* *} \\
{[0.004]^{* *}}\end{array}$ & $\begin{array}{c}-0.006 \\
(0.001)^{* * *} \\
{[0.001]^{* * *}}\end{array}$ & $\begin{array}{c}-0.009 \\
(0.005)^{*} \\
{[0.004]^{* *}}\end{array}$ & $\begin{array}{c}-0.006 \\
(0.001)^{* * *} \\
{[0.001]^{* * *}}\end{array}$ & $\begin{array}{c}-0.010 \\
(0.005)^{* *} \\
{[0.004]^{* * *}}\end{array}$ \\
\hline Baseline Mean & 0.147 & 0.147 & 0.147 & 0.147 & 0.147 & 0.147 \\
\hline \multicolumn{7}{|l|}{ (C) Property Crimes } \\
\hline PM2.5 & $\begin{array}{c}-0.012 \\
(0.001)^{* * *} \\
{[0.001]^{* * *}}\end{array}$ & $\begin{array}{c}-0.016 \\
(0.006)^{* *} \\
{[0.005]^{* * *}}\end{array}$ & $\begin{array}{c}-0.012 \\
(0.001)^{* * *} \\
{[0.001]^{* * *}}\end{array}$ & $\begin{array}{c}-0.016 \\
(0.006)^{* *} \\
{[0.005]^{* * *}}\end{array}$ & $\begin{array}{c}-0.012 \\
(0.001)^{* * *} \\
{[0.001]^{* * *}}\end{array}$ & $\begin{array}{c}-0.017 \\
(0.006)^{* * *} \\
{[0.005]^{* * *}}\end{array}$ \\
\hline Weather Controls & $\checkmark$ & $\checkmark$ & $\checkmark$ & $\checkmark$ & $\checkmark$ & $\checkmark$ \\
\hline Police Station FE & $\checkmark$ & $\checkmark$ & $\checkmark$ & $\checkmark$ & $\checkmark$ & $\checkmark$ \\
\hline Year FE & $\checkmark$ & $\checkmark$ & $\checkmark$ & $\checkmark$ & $\checkmark$ & $\checkmark$ \\
\hline Month FE & $\checkmark$ & $\checkmark$ & $\checkmark$ & $\checkmark$ & $\checkmark$ & $\checkmark$ \\
\hline Week FE & $\checkmark$ & $\checkmark$ & $\checkmark$ & $\checkmark$ & $\checkmark$ & $\checkmark$ \\
\hline Day of Week FE & $\checkmark$ & $\checkmark$ & $\checkmark$ & $\checkmark$ & $\checkmark$ & $\checkmark$ \\
\hline Baseline Mean & 0.198 & 0.198 & 0.198 & 0.198 & 0.198 & 0.198 \\
\hline Radius & $50 \mathrm{KM}$ & $50 \mathrm{KM}$ & $40 \mathrm{KM}$ & $40 \mathrm{KM}$ & $75 \mathrm{KM}$ & $75 \mathrm{KM}$ \\
\hline F-Statistic: First Stage & & 558.117 & & 545.831 & & 603.070 \\
\hline Police Stations & 964 & 964 & 964 & 964 & 964 & 964 \\
\hline $\mathrm{N}$ & $1,760,264$ & $1,760,264$ & $1,760,264$ & $1,760,264$ & $1,760,264$ & $1,760,264$ \\
\hline
\end{tabular}

Notes: Heteroskedasticity robust standard errors clustered by the police station are in parentheses. Standard errors that correct for spatial and serial correlation are in square brackets (Barrios et al. (2012), Hsiang (2010), and Kelly (2019)). ( $\left.{ }^{*} \mathrm{p}<.10^{* *} \mathrm{p}<.05^{* * *} \mathrm{p}<.01\right)$. Each observation in all columns corresponds to the unique date and is at the police station level. The dependent variable in Panel (A) is the total number of FIRs registered at the police station on a given day. The dependent variable in Panel (B) is the total number of FIRs registered under the IPC sections that pertain to violent crimes at the police station on a given day. The dependent variable in Panel (C) is the total number of FIRs registered under the IPC sections that pertain to property crimes at the police station on a given day. Each column regresses the dependent variable on the PM2.5 concentration measure, weather controls, and set of fixed effects. PM2.5 concentration measure has been standardized to have a standard deviation of 1 . Weather controls contain cumulative precipitation, temperature, dew point temperature, sea level pressure, and wind speed in flexible non-parametric form, with the indicator for the observation to be in one of the quartiles of the overall distribution over the sample period. The sample contains data from January 2015 to December 2019. 
Table 9: Effect of PM2.5 concentration on number of FIR - Alternate Radius

\begin{tabular}{|c|c|c|c|c|c|c|}
\hline & $\begin{array}{c}(1) \\
(\mathrm{OLS})\end{array}$ & $\begin{array}{l}(2) \\
(\mathrm{IV})\end{array}$ & $\begin{array}{c}(3) \\
(\mathrm{OLS})\end{array}$ & $\begin{array}{l}(4) \\
\text { (IV) }\end{array}$ & $\begin{array}{c}(5) \\
(\mathrm{OLS})\end{array}$ & $\begin{array}{l}(6) \\
\text { (IV) }\end{array}$ \\
\hline \multicolumn{7}{|l|}{ (A) All Crimes } \\
\hline PM2.5 & $\begin{array}{c}-0.434 \\
(0.110)^{* * *}\end{array}$ & $\begin{array}{c}-0.855 \\
(0.257)^{* * *}\end{array}$ & $\begin{array}{c}-0.427 \\
(0.109)^{* * *}\end{array}$ & $\begin{array}{c}-0.848 \\
(0.256)^{* * *}\end{array}$ & $\begin{array}{c}-0.453 \\
(0.112)^{* * *}\end{array}$ & $\begin{array}{c}-0.870 \\
(0.261)^{* * *}\end{array}$ \\
\hline Baseline Mean & 8.148 & 8.148 & 8.148 & 8.148 & 8.148 & 8.148 \\
\hline \multicolumn{7}{|l|}{ (B) Violent Crimes } \\
\hline PM2.5 & $\begin{array}{c}-0.122 \\
(0.052)^{* *}\end{array}$ & $\begin{array}{c}-0.364 \\
(0.111)^{* * *}\end{array}$ & $\begin{array}{c}-0.120 \\
(0.052)^{* *}\end{array}$ & $\begin{array}{c}-0.360 \\
(0.111)^{* * *}\end{array}$ & $\begin{array}{c}-0.128 \\
(0.053)^{* *}\end{array}$ & $\begin{array}{c}-0.370 \\
(0.113)^{* * *}\end{array}$ \\
\hline Baseline Mean & 3.023 & 3.023 & 3.023 & 3.023 & 3.023 & 3.023 \\
\hline \multicolumn{7}{|l|}{ (C) Property Crimes } \\
\hline PM2.5 & $\begin{array}{c}-0.255 \\
(0.067)^{* * *}\end{array}$ & $\begin{array}{c}-0.496 \\
(0.146)^{* * *}\end{array}$ & $\begin{array}{c}-0.252 \\
(0.066)^{* * *}\end{array}$ & $\begin{array}{c}-0.492 \\
(0.146)^{* * *}\end{array}$ & $\begin{array}{c}-0.264 \\
(0.069)^{* * *}\end{array}$ & $\begin{array}{c}-0.503 \\
(0.148)^{* * *}\end{array}$ \\
\hline Weather Controls & $\checkmark$ & $\checkmark$ & $\checkmark$ & $\checkmark$ & $\checkmark$ & $\checkmark$ \\
\hline District FE & $\checkmark$ & $\checkmark$ & $\checkmark$ & $\checkmark$ & $\checkmark$ & $\checkmark$ \\
\hline Year FE & $\checkmark$ & $\checkmark$ & $\checkmark$ & $\checkmark$ & $\checkmark$ & $\checkmark$ \\
\hline Month FE & $\checkmark$ & $\checkmark$ & $\checkmark$ & $\checkmark$ & $\checkmark$ & $\checkmark$ \\
\hline Week FE & $\checkmark$ & $\checkmark$ & $\checkmark$ & $\checkmark$ & $\checkmark$ & $\checkmark$ \\
\hline Day of Week FE & $\checkmark$ & $\checkmark$ & $\checkmark$ & $\checkmark$ & $\checkmark$ & $\checkmark$ \\
\hline Baseline Mean & 4.053 & 4.053 & 4.053 & 4.053 & 4.053 & 4.053 \\
\hline $\begin{array}{l}\text { Radius } \\
\text { F-Statistic: First Stage }\end{array}$ & $50 \mathrm{KM}$ & $\begin{array}{l}50 \mathrm{KM} \\
87.999\end{array}$ & $40 \mathrm{KM}$ & $\begin{array}{l}40 \mathrm{KM} \\
88.226\end{array}$ & $75 \mathrm{KM}$ & $\begin{array}{l}75 \mathrm{KM} \\
87.234\end{array}$ \\
\hline Districts & 47 & 47 & 47 & 47 & 47 & 47 \\
\hline $\mathrm{N}$ & 85,822 & 85,822 & 85,822 & 85,822 & 85,822 & 85,822 \\
\hline \multicolumn{7}{|c|}{$\begin{array}{l}\text { Notes: Heteroskedasticity robust standard errors clustered by the districts are in parentheses. }\left({ }^{*} \mathrm{p}<.10^{* *}\right. \\
\left.\mathrm{p}<.05^{* * *} \mathrm{p}<.01\right) \text {. Each observation in all columns corresponds to the unique date and is at the district } \\
\text { level. The dependent variable in Panel (A) is the total number of FIRs registered in the district on a given } \\
\text { day. The dependent variable in Panel (B) is the total number of FIRs registered under the IPC sections } \\
\text { that pertain to violent crimes in the district on a given day. The dependent variable in Panel }(\mathrm{C}) \text { is the } \\
\text { total number of FIRs registered under the IPC sections that pertain to property crimes in the district on a } \\
\text { given day. Each column regresses the dependent variable on the PM2.5 concentration measure, weather } \\
\text { controls, and set of fixed effects. PM2.5 concentration measure has been standardized to have a standard } \\
\text { deviation of } 1 \text {. Weather controls contain cumulative precipitation, temperature, dew point temperature, } \\
\text { sea level pressure, and wind speed in flexible non-parametric form, with the indicator for the observation } \\
\text { to be in one of the quartiles of the overall distribution over the sample period. The sample contains data } \\
\text { from January } 2015 \text { to December } 2019 \text {. Districts in all columns refer to police districts. }\end{array}$} \\
\hline
\end{tabular}


Table 10: Effect of PM2.5 concentration on number of FIR - Placebo Regressions

\begin{tabular}{|c|c|c|c|c|c|c|c|c|}
\hline & $\begin{array}{c}(1) \\
\text { OLS }\end{array}$ & $\begin{array}{l}\text { (2) } \\
\text { OLS }\end{array}$ & $\begin{array}{l}\text { (3) } \\
\text { OLS }\end{array}$ & $\begin{array}{l}(4) \\
\text { OLS }\end{array}$ & $\begin{array}{c}(5) \\
\text { OLS }\end{array}$ & $\begin{array}{c}\text { (6) } \\
\text { OLS }\end{array}$ & $\begin{array}{c}\text { (7) } \\
\text { OLS }\end{array}$ & $\begin{array}{c}(8) \\
\text { OLS }\end{array}$ \\
\hline PM2.5 & $\begin{array}{l}-0.000 \\
(0.000)\end{array}$ & $\begin{array}{c}-0.000 \\
(0.000)\end{array}$ & $\begin{array}{l}-0.000 \\
(0.000)\end{array}$ & $\begin{array}{l}-0.000 \\
(0.000)\end{array}$ & $\begin{array}{l}-0.001 \\
(0.001)\end{array}$ & $\begin{array}{l}-0.000 \\
(0.001)\end{array}$ & $\begin{array}{c}-0.002 \\
(0.002)\end{array}$ & $\begin{array}{r}-0.003 \\
(0.003)\end{array}$ \\
\hline Weather Controls & $\checkmark$ & $\checkmark$ & $\checkmark$ & $\checkmark$ & $\checkmark$ & $\checkmark$ & $\checkmark$ & $\checkmark$ \\
\hline Police Station FE & $\checkmark$ & $\checkmark$ & $\checkmark$ & $\checkmark$ & & & & \\
\hline District FE & & & & & $\checkmark$ & $\checkmark$ & $\checkmark$ & $\checkmark$ \\
\hline Year FE & $\checkmark$ & $\checkmark$ & $\checkmark$ & $\checkmark$ & $\checkmark$ & $\checkmark$ & $\checkmark$ & $\checkmark$ \\
\hline Week FE & $\checkmark$ & $\checkmark$ & $\checkmark$ & $\checkmark$ & $\checkmark$ & $\checkmark$ & $\checkmark$ & $\checkmark$ \\
\hline Day of Week FE & $\checkmark$ & $\checkmark$ & $\checkmark$ & $\checkmark$ & $\checkmark$ & $\checkmark$ & $\checkmark$ & $\checkmark$ \\
\hline Month FE & $\checkmark$ & $\checkmark$ & $\checkmark$ & $\checkmark$ & $\checkmark$ & $\checkmark$ & $\checkmark$ & $\checkmark$ \\
\hline Baseline Mean & 0.000 & 0.001 & 0.001 & 0.003 & 0.007 & 0.030 & 0.017 & 0.053 \\
\hline Police Stations & 964 & 964 & 964 & 964 & & & & \\
\hline Districts & & & & & 47 & 47 & 47 & 47 \\
\hline $\mathrm{N}$ & $1,760,264$ & $1,760,264$ & $1,760,264$ & $1,760,264$ & 85,822 & 85,822 & 85,822 & 85,822 \\
\hline
\end{tabular}

Notes: Heteroskedasticity robust standard errors clustered by the police station in column (1) to column (4) and by the districts in column (5) to column (8) are in parentheses. ${ }^{*} \mathrm{p}<.10^{* *} \mathrm{p}<.05^{* * *} \mathrm{p}<.01$ ). Each observation in column (1) to column (4) corresponds to the unique date and is at the police station level. Each observation in column (5) to column (8) corresponds to the unique date and is at the district level. The dependent variable in column (1) is the total number of FIRs registered under the IPC sections that pertain to counterfeit crimes at the police station on a given day. The dependent variable in column (2) is the total number of FIRs registered under the IPC sections that pertain to foreign importation crimes at the police station on a given day. The dependent variable in column (3) is the total number of FIRs registered under the IPC sections that pertain to cybercrimes at the police station on a given day. The dependent variable in column (4) is the total number of FIRs registered under the IPC sections that pertain to crimes not likely to be impacted by the air pollution at the police station on a given day. The dependent variable in column (5) is the total number of FIRs registered under the IPC sections that pertain to counterfeit crimes in the district on a given day. The dependent variable in column (6) is the total number of FIRs registered under the IPC sections that pertain to foreign importation crimes in the district on a given day. The dependent variable in column (7) is the total number of FIRs registered under the IPC sections that pertain to cybercrimes in the district on a given day. The dependent variable in column (8) is the total number of FIRs registered under the IPC sections that pertain to crimes not likely to be impacted by the air pollution in the district on a given day. Each column regresses the dependent variable on the PM2.5 concentration measure, weather controls, and set of fixed effects. PM2.5 concentration measure has been standardized to have a standard deviation of 1 . Weather controls contain cumulative precipitation, temperature, dew point temperature, sea level pressure, and wind speed in flexible non-parametric form, with the indicator for the observation to be in one of the quartiles of the overall distribution over the sample period. The sample contains data from January 2015 to December 2019. Districts in column (5) to column (8) refer to police districts. 
Table 11: Effect of PM2.5 concentration on number of FIR - Date of Incident

\begin{tabular}{|c|c|c|c|c|c|c|c|c|c|c|c|c|}
\hline & $\begin{array}{c}(1) \\
\text { OLS } \\
\text { (All } \\
\text { Crimes) }\end{array}$ & $\begin{array}{c}(2) \\
\text { IV } \\
\text { (All } \\
\text { Crimes) }\end{array}$ & $\begin{array}{c}(3) \\
\text { OLS } \\
\text { (Violent } \\
\text { Crimes) }\end{array}$ & $\begin{array}{c}(4) \\
\text { IV } \\
\text { (Violent } \\
\text { Crimes) }\end{array}$ & $\begin{array}{c}(5) \\
\text { OLS } \\
\text { (Property } \\
\text { Crimes) }\end{array}$ & $\begin{array}{c}\text { (6) } \\
\text { IV } \\
\text { (Property } \\
\text { Crimes) }\end{array}$ & $\begin{array}{c}\text { (7) } \\
\text { OLS } \\
\text { (All } \\
\text { Crimes) }\end{array}$ & $\begin{array}{c}\text { (8) } \\
\text { IV } \\
\text { (All } \\
\text { Crimes) }\end{array}$ & $\begin{array}{c}\text { (9) } \\
\text { OLS } \\
\text { (Violent } \\
\text { Crimes) }\end{array}$ & $\begin{array}{c}\text { (10) } \\
\text { IV } \\
\text { (Violent } \\
\text { Crimes) }\end{array}$ & $\begin{array}{c}(11) \\
\text { OLS } \\
\text { (Property } \\
\text { Crimes) }\end{array}$ & $\begin{array}{c}\text { (12) } \\
\text { IV } \\
\text { (Property } \\
\text { Crimes) }\end{array}$ \\
\hline PM2.5 & $\begin{array}{c}-0.011 \\
(0.002)^{* * *} \\
{[0.001]^{* * *}}\end{array}$ & $\begin{array}{c}-0.033 \\
(0.010)^{* * *} \\
{[0.006]^{* * *}}\end{array}$ & $\begin{array}{l}-0.001 \\
(0.001) \\
{[0.001]}\end{array}$ & $\begin{array}{c}-0.010 \\
(0.005)^{* *} \\
{[0.003]^{* * *}}\end{array}$ & $\begin{array}{c}-0.006 \\
(0.001)^{* * *} \\
{[0.001]^{* * *}}\end{array}$ & $\begin{array}{c}-0.016 \\
(0.006)^{* * *} \\
{[0.004]^{* * *}}\end{array}$ & $\begin{array}{c}-0.248 \\
(0.081)^{* * *}\end{array}$ & $\begin{array}{c}-0.884 \\
(0.226)^{* * *}\end{array}$ & $\begin{array}{l}-0.025 \\
(0.036)\end{array}$ & $\begin{array}{c}-0.384 \\
(0.097)^{* * *}\end{array}$ & $\begin{array}{c}-0.128 \\
(0.047)^{* * *}\end{array}$ & $\begin{array}{c}-0.497 \\
(0.123)^{* * *}\end{array}$ \\
\hline $\begin{array}{l}\text { Weather Controls } \\
\text { Police Station FE }\end{array}$ & $\begin{array}{l}\checkmark \\
\checkmark\end{array}$ & $\begin{array}{l}\checkmark \\
\checkmark\end{array}$ & $\begin{array}{l}\checkmark \\
\checkmark\end{array}$ & $\begin{array}{l}\checkmark \\
\checkmark\end{array}$ & $\begin{array}{l}\checkmark \\
\checkmark\end{array}$ & $\begin{array}{l}\checkmark \\
\checkmark\end{array}$ & $\checkmark$ & $\checkmark$ & $\checkmark$ & $\checkmark$ & $\checkmark$ & $\checkmark$ \\
\hline District FE & & & & & & & $\checkmark$ & $\checkmark$ & $\checkmark$ & $\checkmark$ & $\checkmark$ & $\checkmark$ \\
\hline Year FE & $\checkmark$ & $\checkmark$ & $\checkmark$ & $\checkmark$ & $\checkmark$ & $\checkmark$ & $\checkmark$ & $\checkmark$ & $\checkmark$ & $\checkmark$ & $\checkmark$ & $\checkmark$ \\
\hline Week FE & $\checkmark$ & $\checkmark$ & $\checkmark$ & $\checkmark$ & $\checkmark$ & $\checkmark$ & $\checkmark$ & $\checkmark$ & $\checkmark$ & $\checkmark$ & $\checkmark$ & $\checkmark$ \\
\hline Day of Week FE & $\checkmark$ & $\checkmark$ & $\checkmark$ & $\checkmark$ & $\checkmark$ & $\checkmark$ & $\checkmark$ & $\checkmark$ & $\checkmark$ & $\checkmark$ & $\checkmark$ & $\checkmark$ \\
\hline Month FE & $\checkmark$ & $\checkmark$ & $\checkmark$ & $\checkmark$ & $\checkmark$ & $\checkmark$ & $\checkmark$ & $\checkmark$ & $\checkmark$ & $\checkmark$ & $\checkmark$ & $\checkmark$ \\
\hline $\begin{array}{l}\text { Baseline Mean } \\
\text { F-Statistic: First Stage }\end{array}$ & 0.339 & $\begin{array}{c}0.339 \\
558.117\end{array}$ & 0.126 & $\begin{array}{c}0.126 \\
558.117\end{array}$ & 0.166 & $\begin{array}{c}0.166 \\
558.117\end{array}$ & 6.961 & $\begin{array}{c}6.961 \\
87.999\end{array}$ & 2.585 & $\begin{array}{c}2.585 \\
87.999\end{array}$ & 3.412 & $\begin{array}{c}3.412 \\
87.999\end{array}$ \\
\hline Police Stations & 964 & 964 & 964 & 964 & 964 & 964 & & & & & & \\
\hline $\begin{array}{l}\text { Districts } \\
\mathrm{N}\end{array}$ & $1,760,264$ & $1,760,264$ & $1,760,264$ & $1,760,264$ & $1,760,264$ & $1,760,264$ & $\begin{array}{c}47 \\
85,822\end{array}$ & $\begin{array}{c}47 \\
85,822\end{array}$ & $\begin{array}{c}47 \\
85,822\end{array}$ & $\begin{array}{c}47 \\
85,822\end{array}$ & $\begin{array}{c}47 \\
85,822\end{array}$ & $\begin{array}{c}47 \\
85,822\end{array}$ \\
\hline
\end{tabular}

Notes: Heteroskedasticity robust standard errors clustered by the police station in column (1) to column (6) and by the districts in column (7) to column (12) are in parentheses. Standard errors that correct for spatial and serial correlation in column (1) to column (6) are in square brackets (Barrios et al. (2012), Hsiang (2010), and Kelly (2019)). $\left({ }^{*} \mathrm{p}<.10{ }^{* *} \mathrm{p}<.05^{* * *} \mathrm{p}<.01\right)$. We are unable to correct for spatial and serial correlation in column (7) to column (12) because of the non-availability of the police district geoinformation. Each observation in column (1) to column (6) corresponds to the unique date and is at the police station level. Each observation in column (7) to column (12) corresponds to the unique date and is at the district level. The dependent variable in column (1) and column (2) is the total number of FIRs registered at the police station on a given day. The dependent variable in column (3) and column (4) is the total number of FIRs registered under the IPC sections that pertain to violent crimes at the police station on a given day. The dependent variable in column (5) and column (6) is the total number of FIRs registered under the IPC sections that pertain to property crimes at the police station on a given day. The dependent variable in column (7) and column (8) is the total number of FIRs registered in the district on a given day. The dependent variable in column (9) and column (10) is the total number of FIRs registered under the IPC sections that pertain to violent crimes in the district on a given day. The dependent variable in column (11) and column (12) is the total number of FIRs registered under the IPC sections that pertain to property crimes in the district on a given day. Each column regresses the dependent variable on the PM2.5 concentration measure, weather controls, and set of fixed effects. PM2.5 concentration measure has been standardized to have a standard deviation of 1 . Weather controls contain cumulative precipitation, temperature, dew point temperature, sea level pressure, and wind speed in flexible non-parametric form, with the indicator for the observation to be in one of the quartiles of the overall distribution over the sample period. The sample contains data from January 2015 to December 2019. Districts in column (7) to column (12) refer to police districts. 
Table 12: Effect of PM2.5 concentration on number of arrests

\begin{tabular}{lcccc}
\hline & $(1)$ & $(2)$ & $(3)$ & $(4)$ \\
& OLS & IV & OLS & IV \\
\hline PM2.5 & -0.019 & 0.016 & -0.355 & -0.599 \\
& $(0.013)$ & $(0.015)$ & $(0.253)$ & $(0.597)$ \\
Weather Controls & $\checkmark$ & $\checkmark$ & $\checkmark$ & $\checkmark$ \\
Police Station FE & $\checkmark$ & $\checkmark$ & & \\
District FE & & & $\checkmark$ & $\checkmark$ \\
Year FE & $\checkmark$ & $\checkmark$ & $\checkmark$ & $\checkmark$ \\
Week FE & $\checkmark$ & $\checkmark$ & $\checkmark$ & $\checkmark$ \\
Day of Week FE & $\checkmark$ & $\checkmark$ & $\checkmark$ & $\checkmark$ \\
Month FE & $\checkmark$ & $\checkmark$ & $\checkmark$ & $\checkmark$ \\
Baseline Mean & 0.196 & 0.196 & 3.433 & 3.433 \\
F-Statistic: First Stage & & 702.816 & & 41.853 \\
Police Stations & 789 & 789 & & \\
Districts & & & 45 & 45 \\
N & 575,970 & 575,970 & 32,850 & 32,850 \\
\hline
\end{tabular}

Notes: Heteroskedasticity robust standard errors clustered by the police district are in parentheses. (* $\mathrm{p}<.10^{* *} \mathrm{p}<.05^{* * *} \mathrm{p}<.01$ ). Each observation in column (1) and column (2) corresponds to the unique date and is at the police station level. Each observation in column (3) and column (4) corresponds to the unique date and is at the district level. The dependent variable in column (1) and column (2) is the total number of arrests at the police station on a given day. The dependent variable in column (3) and column (4) is the total number of arrests in the district on a given day. Each column regresses the dependent variable on the PM2.5 concentration measure, weather controls, and set of fixed effects. PM2.5 concentration measure has been standardized to have a standard deviation of 1 . Weather controls contain cumulative precipitation, temperature, dew point temperature, sea level pressure, and wind speed, where each of these enters the specification as daily means. The sample contains data from January 2018 to December 2019. Districts in column (3) and column (4) refer to police districts. 


\section{Appendices}

\section{Appendix A Complaints Distribution}

Figure 6: Distribution of number of FIR

(a) By Year

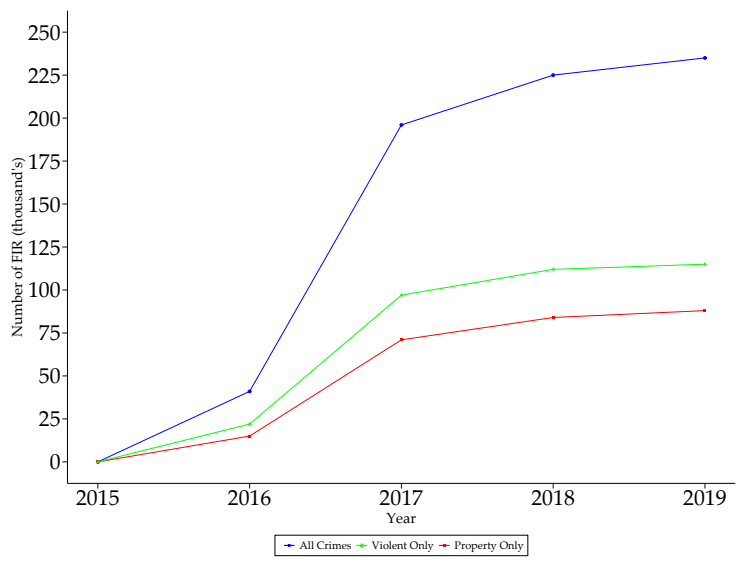

(c) By Week

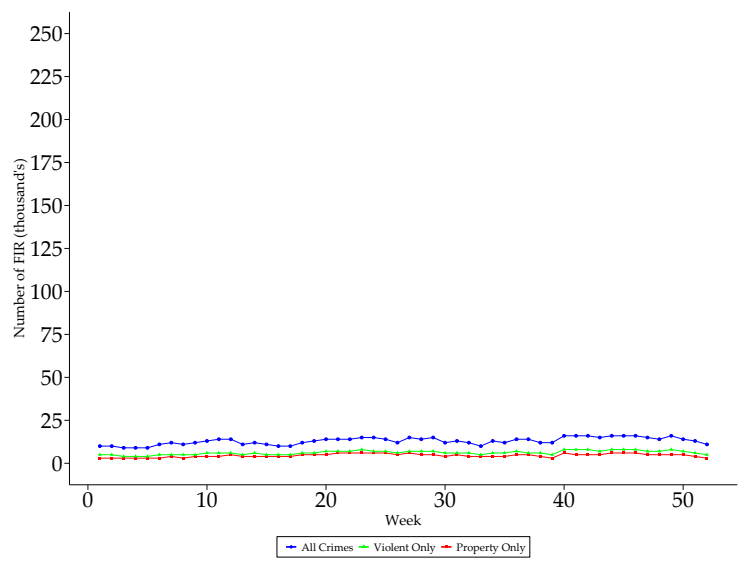

(b) By Month

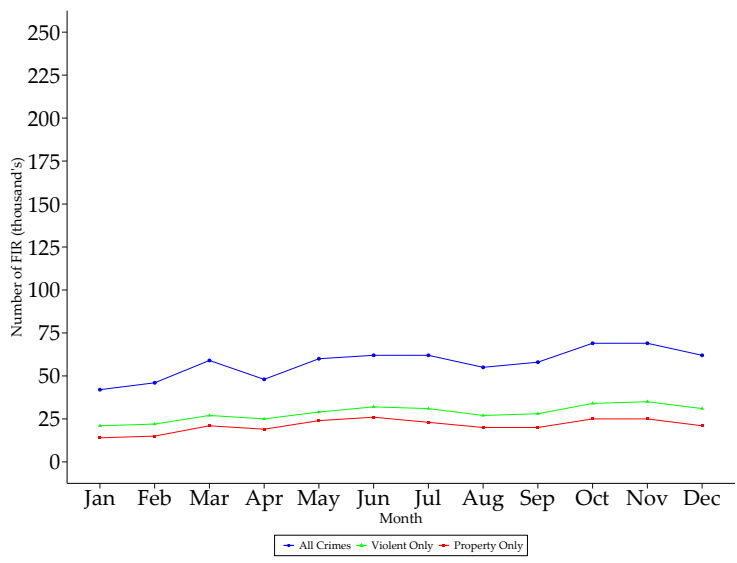

(d) By Day of Week

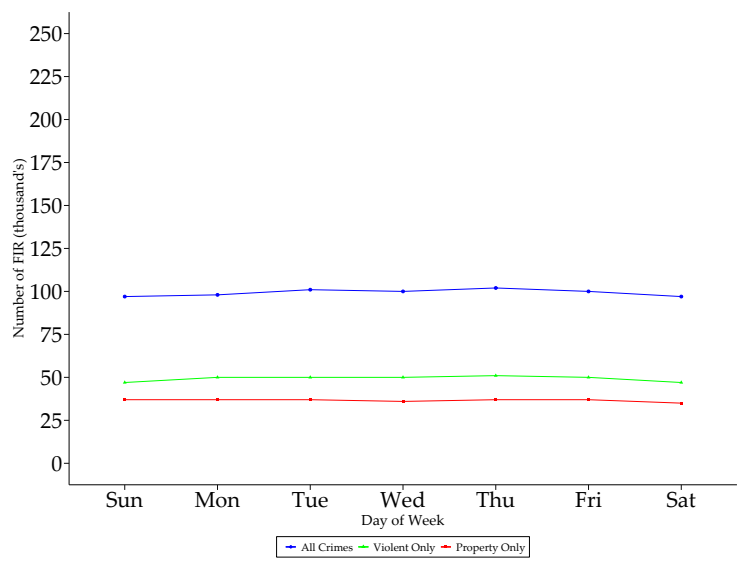

Note: Panel (6a) presents the distribution of all crimes, violent crimes only, and property crimes only by year. Panel (6b) presents the distribution of all crimes, violent crimes only, and property crimes only by month. Panel (6c) presents the distribution of all crimes, violent crimes only, and property crimes only by calendar week. Panel (6d) presents the distribution of all crimes, violent crimes only, and property crimes only by day of the week. The sample contains data from January 2015 to December 2019. 
Figure 7: Distribution of number of complaints received by NCW

(a) By Year

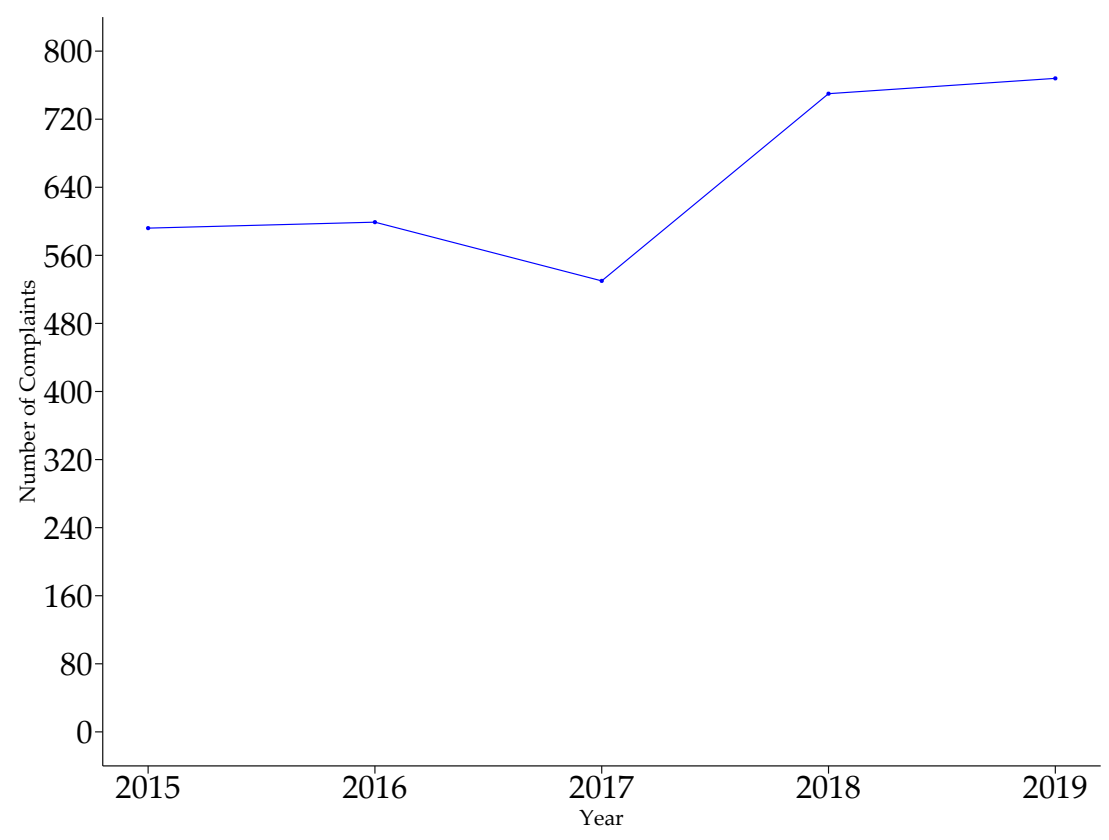

(b) By Month

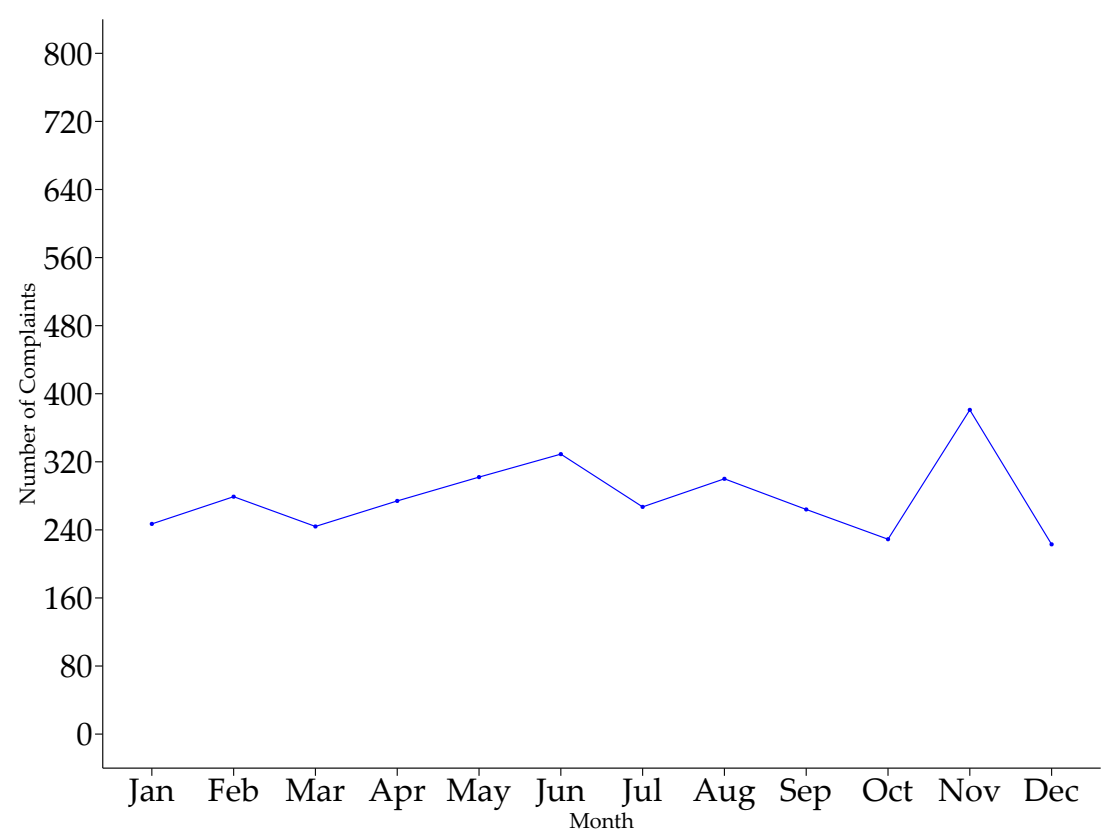

Note: This figure uses data from section (4.1.2). Panel (7a) presents the distribution of complaints by year. Panel $(7 \mathrm{~b})$ presents the distribution of complaints by month. The sample contains data from January 2015 to December 2019. 


\section{Appendix B Air Pollution Distribution}

Figure 8: Mean PM2.5 concentration by Month

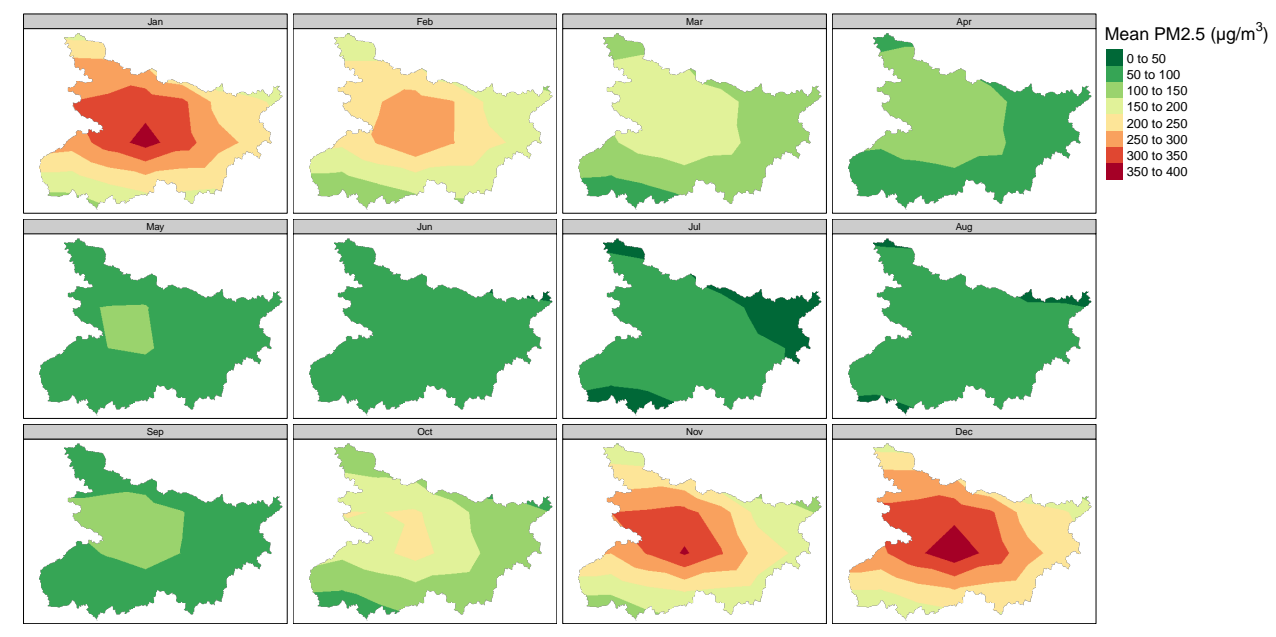

Note: EAC-4 reanalysis data on PM2.5 concentration with a spatial resolution of $0.01^{\circ} \times 0.01^{\circ}$ is used. The sample contains data from January 2015 to December 2019. 
Figure 9: Mean PM2.5 concentration by Year

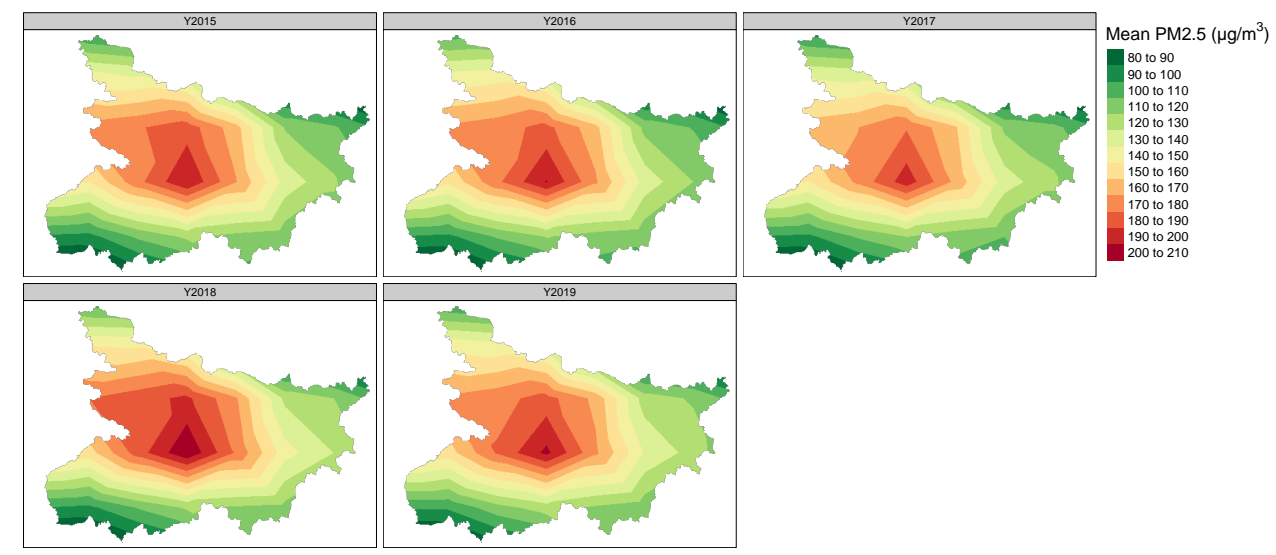

Note: EAC-4 reanalysis data on PM2.5 concentration with a spatial resolution of $0.01^{\circ} \times 0.01^{\circ}$ is used. The sample contains data from January 2015 to December 2019. 
Figure 10: Mean PM2.5 concentration by Day of Week

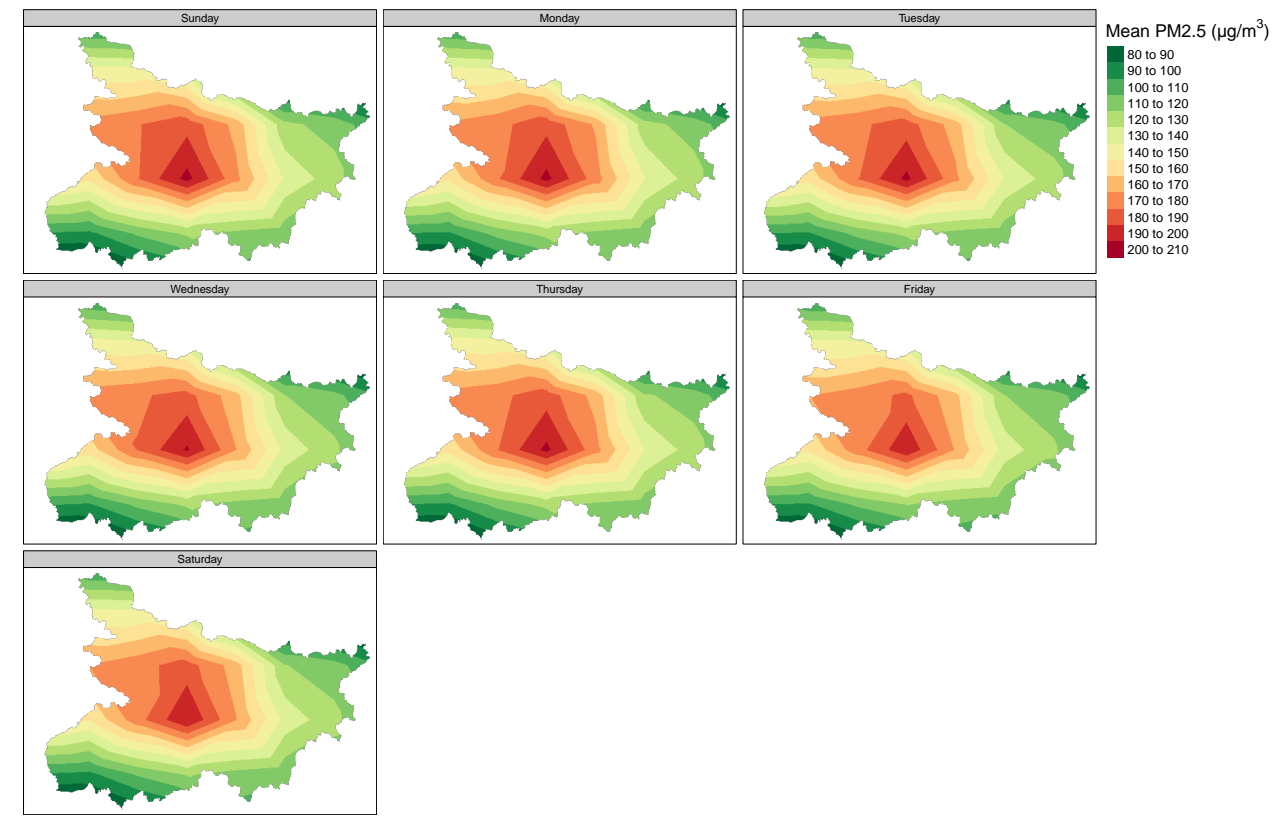

Note: EAC-4 reanalysis data on PM2.5 concentration with a spatial resolution of $0.01^{\circ} \times 0.01^{\circ}$ is used. The sample contains data from January 2015 to December 2019. 


\section{Appendix C Bihar Administrative Divisions}

Figure 11: Administrative divisions in Bihar

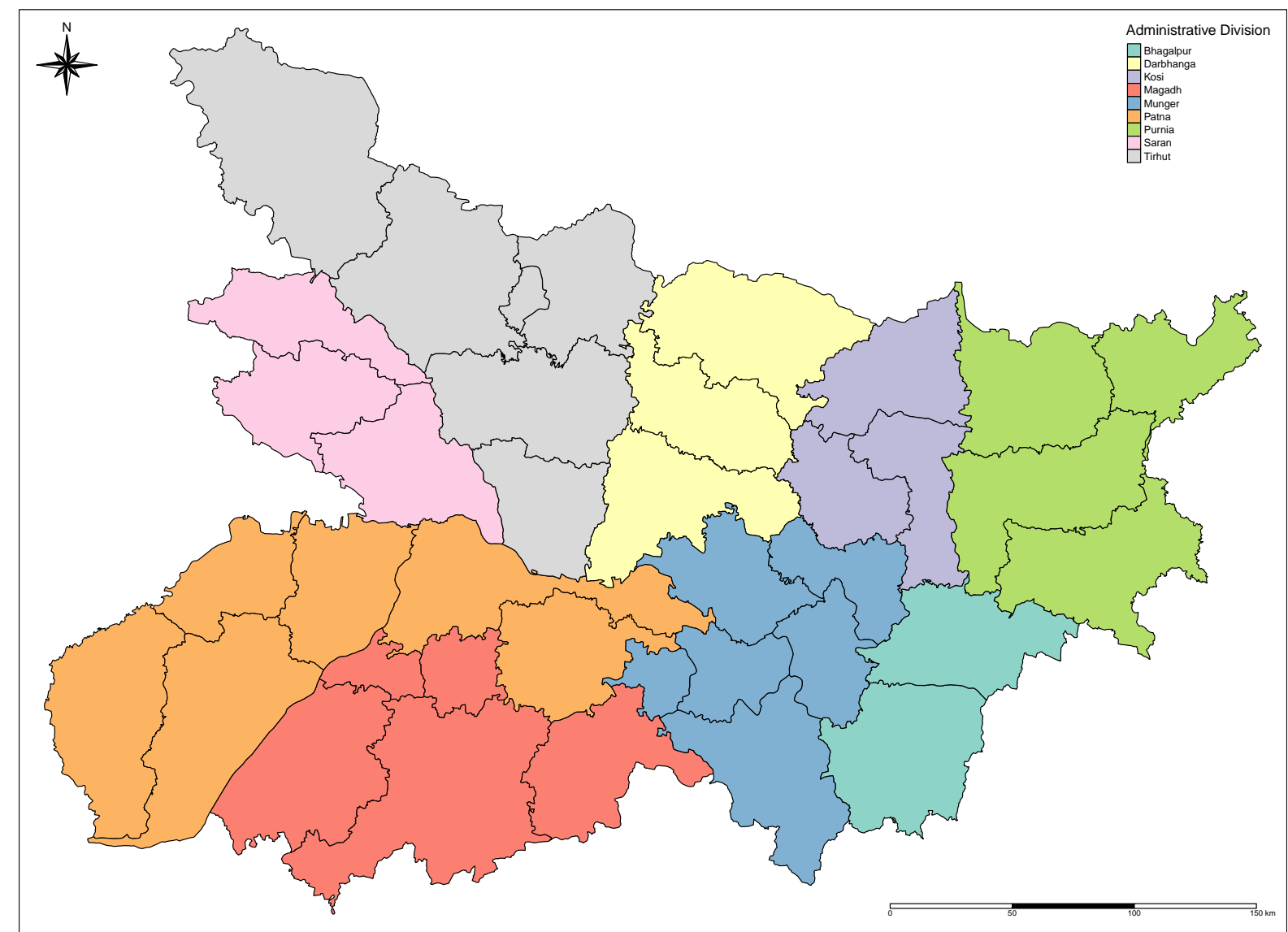

Note: Each of the 38 administrative districts is colored depending upon which administrative division they belong to. 2011 census shapefiles are used to plot the district boundaries. 


\section{Appendix D Instrument Variation}

Figure 12: Instrument variation
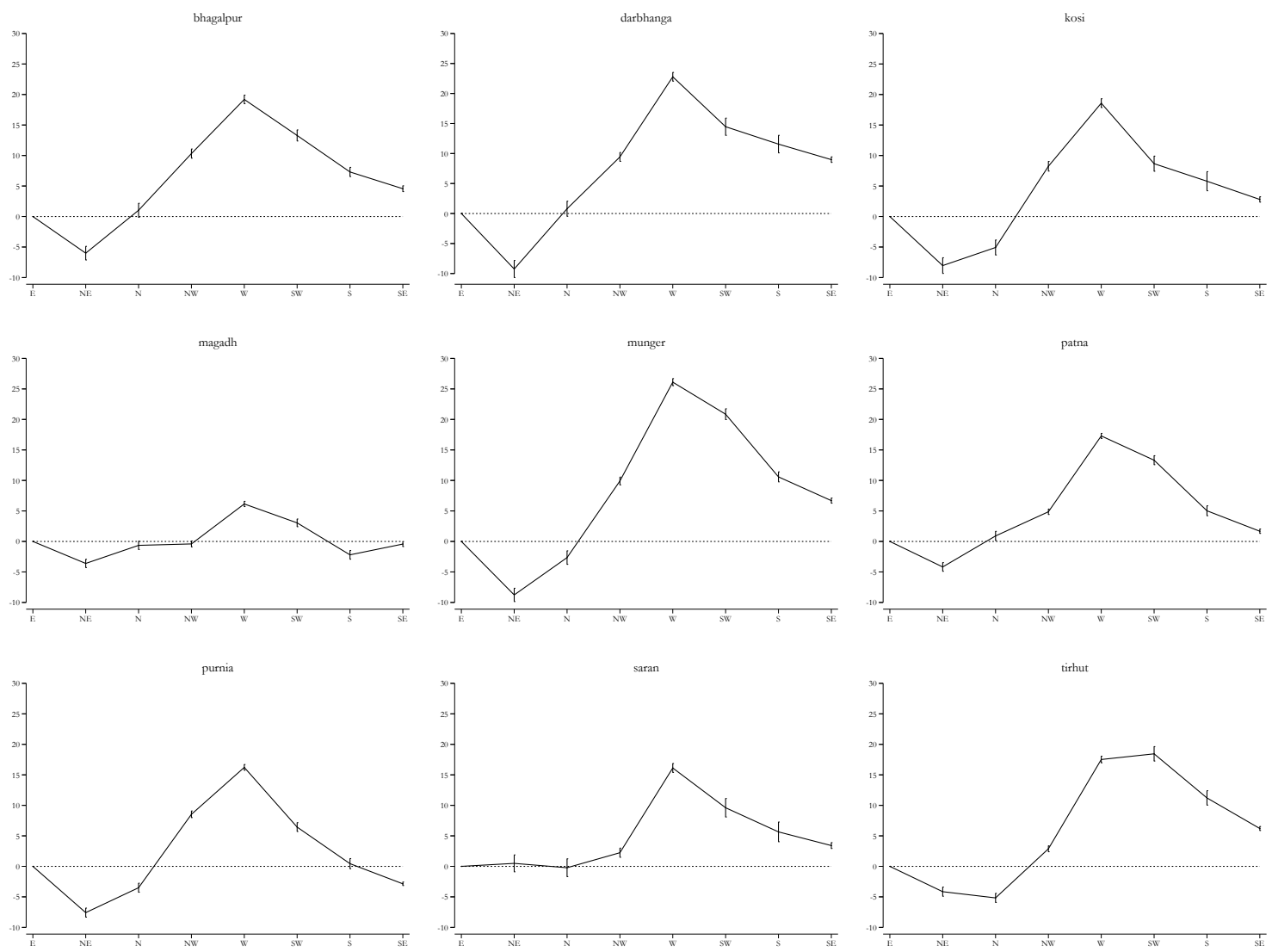

Note: This figure plots the estimates and the associated 95 percent confidence interval based on robust standard errors from equation (4) for each of the nine administrative divisions in Bihar. 


\section{Appendix E Survey Data Descriptive Statistics}

Table 13: Summary Statistics - DHS and IHDS Data

\begin{tabular}{|c|c|c|}
\hline & Mean & SD \\
\hline \multicolumn{3}{|l|}{ (A) DHS 2015-16 Data } \\
\hline Fraction reporting any Domestic Violence & 0.392 & 0.488 \\
\hline Fraction reporting any Physical Violence & 0.372 & 0.484 \\
\hline Fraction reporting ant Emotional Violence & 0.162 & 0.369 \\
\hline Mean PM2.5 (Last 12 months) $\left(\mu \mathrm{g} / \mathrm{m}^{3}\right)$ & 142.275 & 22.162 \\
\hline Number of Household Members & 5.680 & 2.452 \\
\hline Fraction Illiterate & 0.500 & 0.500 \\
\hline Fraction literate till Primary & 0.105 & 0.307 \\
\hline Fraction literate till Secondary & 0.340 & 0.474 \\
\hline Fraction literate above Secondary & 0.055 & 0.228 \\
\hline Fraction Hindu & 0.846 & 0.361 \\
\hline Fraction Muslim & 0.153 & 0.360 \\
\hline Fraction Other Religion & 0.001 & 0.029 \\
\hline \multicolumn{3}{|l|}{ (B) IHDS-2 Data } \\
\hline Local Crime (Last 12 Months) & 0.095 & 0.294 \\
\hline Local Crime - Violent (Last 12 Months) & 0.015 & 0.121 \\
\hline Local Crime - Property (Last 12 Months) & 0.058 & 0.233 \\
\hline LC1 & 0.049 & 0.215 \\
\hline LC2 & 0.016 & 0.126 \\
\hline LC3 & 0.039 & 0.193 \\
\hline $\mathrm{LC} 4$ & 0.301 & 0.459 \\
\hline Mean PM2.5 (Last 12 months) $\left(\mu \mathrm{g} / \mathrm{m}^{3}\right)$ & 137.861 & 20.762 \\
\hline Number of Household Members & 5.492 & 2.525 \\
\hline Fraction Illiterate & 0.345 & 0.475 \\
\hline Fraction literate till Primary & 0.133 & 0.339 \\
\hline Fraction literate till Secondary & 0.276 & 0.447 \\
\hline Fraction literate above Secondary & 0.246 & 0.431 \\
\hline Fraction Hindu & 0.839 & 0.368 \\
\hline Fraction Muslim & 0.160 & 0.367 \\
\hline Fraction Other Religion & 0.001 & 0.025 \\
\hline
\end{tabular}

Notes: 4728 observations in panel (A) and 1546 observations in panel (B). In both panels, each observation corresponds to a unique respondent. Panel (A) presents summary statistics of data from the 2015-16 round of DHS and for the observations from the state of Bihar. Panel (B) presents summary statistics of data from the IHDS-2 and for the observations from the state of Bihar. LC1 in panel (B) is whether the respondent reported anything was stolen from the household in the last twelve months. LC2 in panel (B) is whether the respondent reported anyone breaking or getting in the house illegally in the last twelve months. LC3 in panel (B) is whether the respondent reported anyone in the household was threatened or attacked in the last twelve months. LC4 in panel (B) is whether the respondent reported frequent harassment of unmarried girls in the neighborhood. 